Examining transition pathways to construction innovation in Russia: A system dynamics approach

Emiliya Suprun ${ }^{\mathrm{a}, \mathrm{b}, \mathrm{c}, *}$, Oz Sahin ${ }^{\mathrm{a}, \mathrm{b}, \mathrm{c}}$, Rodney Anthony Stewart ${ }^{\mathrm{a}, \mathrm{b}, \mathrm{c}}$ and Kriengsak Panuwatwanich $^{\mathrm{d}}$

${ }^{a}$ School of Engineering and Built Environment, Griffith University, Gold Coast, Queensland, Australia

${ }^{b}$ Cities Research Institute, Griffith University, Gold Coast, Queensland, Australia

${ }^{c}$ GCCRP Systems Modelling Group, Griffith University, Gold Coast, Queensland, Australia

${ }^{d}$ School of Civil Engineering and Technology, SIIT, Thammasat University, Pathum Thani, Thailand

*Corresponding author.e.suprun@griffith.edu.au (E. Suprun) 


\section{Examining transition pathways to construction innovation in Russia: A system dynamics approach}

The construction industry has often been criticized for its lack of innovation and commitment to R\&D. Using a systems approach, this study examined a number of construction innovation system scenarios and policy interventions within the context of four future plausible Russian construction industry transition pathways (i.e. business as usual, market forces, conservative development and innovation power). An integrated participatory systems modelling approach was employed to develop the system dynamics (SD) model incorporating the main actors of the construction innovation process, namely, industry, government and university. Construction innovation diffused more rapidly and seeded more innovators than imitators for the innovation power transition pathway, whereby increasing government $R \& D$ support was coupled with extensive reductions in barriers. The market forces and state-led conservative development transition pathways showed similar levels of innovation outcomes within the modelling horizon, but predominately yielded innovation imitators. The extensive scenario analysis findings culminated in the formulation of policy recommendations for enhancing innovativeness in the Russian construction industry.

Keywords: System dynamics; construction innovation; participatory modelling; scenario analysis; transition pathways

\section{Introduction}

\section{Construction innovation processes}

Construction is one of the largest economic sectors in the Russian Federation, however, it is very diverse and fragmented (Expert 2007; Grigoryev 2011; HSE 2013; Suprun and Stewart 2015; RSCI 2017). It is generally accepted that the industry worldwide does not have a coherent 
model of innovation development, is unwilling to innovate and shows a conservative attitude towards mass inclusion of cutting-edge technology into construction processes (Blayse and Manley 2004; Ozorhon et al. 2010; Orstavik et al. 2015; Ozorhon and Oral 2017). Nevertheless, a high level of innovation performance is extremely important for the industry's growth and the development a country economy. Many studies have been undertaken to examine innovationrelated topics in the field of construction management (Egbu 2004; Stewart 2007; Panuwatwanich et al. 2008, 2009a, 2009b; Davidson 2013; Ozorhon 2013; Davis et al. 2016; Dansoh et al. 2017; Yusof et al. 2017). It is worth noting, that most of the aforementioned studies have addressed innovation processes in the industry by mainly focusing at the project and firm level. Nevertheless, according to Seaden and Manseau (2001), the innovation process is complex involving governmental and other institutional actors that interact by jointly and individually contributing to the development and diffusion of innovations. In other words, the innovation process involves interactive relations among different actors and follows a nonlinear path (Lim et al. 2006; Lim et al. 2007; Van Egmond 2012; Loosemore 2013). From this perspective, the innovation performance of the industry depends not only on how individual firms perform in isolation, but on how they interact with other actors. Hence, the current study is founded on the innovation system approach (Lundvall 1992; Nelson 1993; Malerba 2002; Uriona Maldonado and Grobbelaar 2018) which stresses that understanding the relationships among the actors involved in the innovation process is the key to improvement of innovation performance of an industry. To be precise, the scope of the theoretical framework developed for the Russian construction innovation system has a strong focus on the linkages among the government, industry and academia (Suprun et al. 2016).

The construction industry, as well as other types of industries, develop continuously and as such is subject to dynamic processes (Lim et al. 2007; Lim and Peltner 2011; Orstavik et al. 2015). Considering the multi-actor and dynamic nature of the construction sector, analysis of 
innovation performance should be undertaken from a non-linear and systemic perspective. In other words, a systems modelling approach is suitable for capturing dynamics within the construction innovation system. To the authors' knowledge, this is the first comprehensively developed SD model that examines the relationships between the construction industry, academia and government, and has a focus on the challenging Russian Federation country context. In such a context, a robustly developed SD model is needed to understand how government policies and supportive programs can encourage industrialists to innovate, promote research and transfer technology, which will ultimately improve industry productivity and competitiveness.

\section{Measurement of innovation performance}

Innovation in construction can take different forms from design, construction methods and technical advances to procurement, project management and leadership (Ozorhon et al. 2010; Davis et al. 2016). However, there is not a single and complete generally accepted method of measuring innovation at the present time. This study considers the following key performance indicators (KPIs) as appropriate to assess innovation performance within the construction industry:

- Industry innovative activity measured as the percentage of enterprises involved in innovation processes (Samara et al. 2012; RSCI 2017)

- Innovation intensity measured as the percentage of total sector turnover spent on the development of industry innovative capabilities, technical competencies and innovation infrastructure (Montalvo and van der Giessen 2011; Gorodnikova et al. 2018)

- $R \& D$ intensity measured as overall (i.e. both industry and government) expenditure devoted to R\&D activities as a percentage of GDP (Lim et al. 2007; Hampson et al. 2014). 
Based on the existing construction management literature (Seaden and Manseau 2001; Panuwatwanich et al. 2009a; Van Egmond 2012; Xue et al. 2014; Orstavik et al. 2015; Yusof et al. 2017) and previously conducted studies (Suprun and Stewart 2015; Suprun et al. 2016), we have identified three main factors that influence or force decision-makers within construction companies to acknowledge innovation implementation as a priority to improve efficiency and effectiveness:

- Attractiveness. There is a need to create an environment where organizations have interest in exploring innovation, have successful access to innovative technologies, and are able to maintain a high-tech business. In other words, innovations must be attractive.

- Innovative capability. Construction firms need to allocate capabilities throughout the entire construction innovation system in order to achieve the benefits of a high-level innovation performance. In other words, it is necessary to have an ability to recognize the value of knowledge and apply it strategically.

- Pressure. Given the growing domestic and international competition in the world of construction, only companies allocating sufficient investment into the new technology and highly skilled personnel may expect to have a stable position in the market. Additionally, there might be environmental, political and social pressure towards innovation.

\section{Current conditions of construction innovation in Russia}

The Russian construction sector has been facing various challenges which hinder innovation processes. The industry's unwillingness to implement innovative technological advancements is primarily caused by a lack of innovative capabilities as a precondition for application of new building materials, structures, design methods and construction methods. In the majority of cases, there are inadequate financial resources for contractors to support their innovative 
activities. In fact, the Russian construction sector spends only $0.1 \%$ of its total turnover on product and process innovation (Gorodnikova et al. 2018). In comparison, the industry's innovation intensity in other similar countries such as Latvia, Slovakia and the Czech Republic has an average of $0.8 \%$, while in developed countries it is more that $2 \%$ (Montalvo and van der Giessen 2011). Hence, efficient financial stimulating mechanisms need to be further reinforced in the sector.

In addition to weak investment activity, there are excessive administrative barriers, inappropriate technical regulation, and variance of construction norms and codes to international standards. Due to a number of measures taken by the government to simplify the process of obtaining building licenses and documentation, Russia takes 115 th place out of 186 for the time and ease of such procedures, compared to 156th place in 2015 (Doing Business 2018). Nevertheless, 230 days are still spent dealing with the construction permits while for Europe and Central Asia it is 168 days on average. In comparison, it takes 27.5 days in South Korea (28th place), 86 days in the UK (14th place), 121 days in Australia (6th place), and 161 days in the Netherlands (76th place). In addition to administrative obstacles, low construction productivity, which is also a result of insufficient levels of innovation, causes the slow construction processes.

Another top challenge in innovation integration is procurement methods based on price competition that lead to declining productivity and quality of construction works (Suprun and Stewart 2015). It makes innovative companies hard to compete due to innovative solutions expansiveness at the initiation stage. Under such circumstances, only leading companies can afford the cost of R\&D and the development of innovative capabilities at a fast pace. Moreover, the 'cost over quality' purchasing practice may be a reason for the growth of corruption in the sector. 
The problem of significant underinvestment in R\&D also holds true for the Russian construction innovation system. The conducted study (Suprun and Stewart 2015) indicates weak interest in R\&D on the side of the industry. Despite the promising scientific and research potential of research institutions and universities, the transfer of innovative laboratory ideas to the practical environment is only possible with the industry readiness to implement the results of R\&D. In Russia, the overall expenditure devoted to R\&D activities as a percentage of GDP is less than $0.5 \%$ while in developed countries such as Germany, Australia, Denmark and the USA it exceeds 2\% (Hampson et al. 2014; Berezina et al. 2017).

\section{Transition pathways}

This paper develops an SD model that integrates the concept of a construction innovation system with the notion of macro industry transition pathways. Both qualitative and quantitative transition modelling techniques have recently been used for understanding different plausible 'futures' under alternative scenarios. The majority of transition research has been done within the fields of sustainable development (Farla et al. 2012; Costanza et al. 2016), global ecosystem services (Geels et al. 2016; Kubiszewski et al. 2017), and the energy sector ( $\mathrm{Li}$ et al. 2015; Moallemi et al. 2017).

Stakeholder consultation resulted in the formulation of four future industry transition pathways for this study, with each one attempting to encapsulate its relevant innovation conditions (i.e. government policy and incentives, firm characteristics, etc.) and causal outcomes (i.e. attractiveness of being innovative, innovation and R\&D intensity, etc.).

To explore transition pathways, the scenarios were developed considering the variation of key factors. Two of these important but uncertain factors driving R\&D in the construction sector were: (1) the conditions and level of government financial support; and (2) demand for innovation related to market expectations largely dictated by procurement processes. 
Considering the level of government support for construction innovation, this is a critical issue given the ever-changing political context in Russia accompanied by sanctions pressure and a difficult financial climate (RSCI 2015; Suprun and Stewart 2015; RSCI 2017). Sufficient government incentive mechanisms would invoke firms to make long-term innovation investments and move away from only short-term profit considerations. Market competition is another main driver of innovation in the construction sector, and if the Russian government can create a more seamless market economy, then construction service providers will embrace an innovative culture without the need for extensive government intervention. The descriptions of the four transition pathways scenarios are detailed in Section 3.

\section{Research goal}

The overarching goal of this paper is to understand the mechanisms and rate of innovation development in the context of four transition pathway scenarios of the Russian Federation construction industry. In particular, the research sought to determine which enabling factors would drive greater rates of innovation diffusion in the construction industry. An important feature of the SD modelling, was that it catered for the exploration of the policy levers that would derive the development of new innovative products to the market rather than merely imitation-based innovation adoption. This is important in the Russian Federation country context since there is always the political risk that severe sanctions may limit international technology transfer and require heightened national R\&D efforts. Readers should be aware that the conducted SD modelling was not intended for the precise forecasting of future innovation outcomes; rather it was undertaken to derive greater understanding of the Russian construction innovation system within the context of four plausible transition pathways of the construction market.

\section{Structure of the paper}


Following this introduction, Section 2 explains the modelling approach. Sections 3 provides a narrative of the four future transition pathway scenarios. Section 4 presents an overview of the SD model, mathematical formulation of the key variables, and the model validation procedure. Section 5 presents results and discussion around scenario analysis covering a period of 30 years, and policy recommendations. Finally, Section 6 concludes the findings of the research, discusses limitations and provides future research directions.

\section{Research approach}

\section{IPSM process}

The core of the integrated participatory systems modelling (IPSM) process applied in this research is the development of an SD model that captures the complexity of the interactions between government, academia and industry within the construction innovation system in an integrated manner (Figure 1). SD modelling is well suited for understanding the cause-andeffect mechanisms that generate the dynamic behavior of the complex innovation diffusion process in the Russian Federation construction industry under various scenarios. Stages 1 and 2 of the IPSM process are detailed in papers previously published by authors (Suprun and Stewart 2015; Suprun et al. 2016; Suprun et al. 2018). This current paper is focused on the results of Stages 3 to 5 of the IPSM approach detailed in Suprun et al. (2018).

[Figure 1 near here]

\section{SD modelling}

In general, SD modelling is a methodology that represents a set of conceptual and numerical methods that are used to examine and analyze the structure of a complex system and behavioral relationships between certain variables over time (Sterman 2000). According to Jay Forrester 
(1961), the founder of system dynamics, the modelling technique is based on the following key principles: feedback control theory, understanding the decision making process, and the use of computer-based technologies to develop simulation models. Moreover, SD models allow for investigating feedback loops, flows and stocks structure, non-linear effects, time delays and, as a result, high complexity (Maani and Cavana 2007).

First of all, the main characteristic of the SD modelling is systems or causal feedback thinking. Feedback is a process where the system output variable is fed back in as an input variable via certain processes, resulting in the emergence of a closed path of actions and information between those variables (Maani and Cavana 2007). These closed paths are known as feedback loops. In order to reach understanding of the system under study, it is essential to distinguish between two different types of feedback loops when developing SD models and analyzing the behavior over time (Sterman 2000): reinforcing (also known as positive) feedback loops and balancing (also known as negative) feedback loops. Reinforcing feedback loops accelerate changes within a system to produce growth or decline, while balancing feedback loops should be understood as a counteract change within a system to produce stabilizing behavior or force target seeking.

SD models enable numerical analysis of a system of integral or differential equations. To develop a numerical model, a modeler converts a conceptual model or a dynamic hypothesis into a 'stocks and flows' representation also known as a stock and flow diagram (SFD) (Morecroft 2008). Variables that accumulate over time and represent the system state are performed by 'stocks' (also known as accumulators or levels) and the processes that influence change in these stocks are represented by 'flows' (also known as rates). Mathematically speaking, differential equations are used to show the rate of change in stocks numerically that integrate their inflows and outflows. Together, stocks and flows reveal the true dynamics of a system, while other variables in the system provide auxiliary information needed to create the 
equations. At each time step the equations are calculated based on current values, including integration over time (Sterman 2000).

In fact, not all the relationships between system elements generate linear behavior in real time due to the existence of numerous positive and negative feedback loops in combination with significant time lags (Grösser 2017). In other words, activities in the decision-making process do not remain isolated as a linear process of cause and effect (Sahin et al. 2018b). A time lag (also known as a time delay) is described by time needed for decisions and actions to affect the status of a system. For instance, building innovative capability takes a lot of time along with developing new goods or services. Together, feedback loops, time delays and the nonlinearity between the system elements, create the complex dynamics of this system.

In terms of this research, the mentioned five concepts (i.e. feedback loops, stocks and flows, time delays, nonlinearity, and complexity) together contribute to reveal the true nature of construction innovation processes as a complex multi-loop system interconnected within a structure that reinforces multiple feedback processes. Active stakeholder engagement facilitated the formulation of the SD model. The study participants were: researchers and academics specializing in construction management; civil and structural engineers; designers, project managers and directors of construction companies; and public servants with roles related to the construction industry and innovation development. Readers should note that detailed profile of the stakeholders involved in the case study is presented in the paper previously published by authors (Suprun et al. 2018).

SD has long been used to address complex problems in the construction sector. Many researchers have developed SD models to address construction workers' safety culture, safe behaviors, and accidents on construction sites (Mohamed and Chinda 2011; Maryani et al. 2015; Nasirzadeh et al. 2018). Some research has been carried out to understand the dynamic competitive nature of the construction sector (Dangerfield et al. 2010; Gilkinson and 
Dangerfield 2013). The modelling technique has also been widely used to address various aspects of construction project management such as project planning, scheduling, risk assessment, along with performance of construction projects (Han et al. 2014; Etemadinia and Tavakolan 2018; Leon et al. 2018). However, to the authors' knowledge, no attempts have yet been made to model the dynamics of the construction innovation system, especially in the Russian Federation country context.

\section{Transition pathway scenario planning}

As mentioned above, transition pathway scenarios emerge by crossing two influential and uncertain driving forces to illustrate a set of plausible 'futures' that ultimately incorporate different policies along with the industry views in a simplified way. Four scenarios represent four futures covering a range of issues, including an orientation and preferences of the industry, level of innovative activity, government support, to name a few (Figure 2): (1) Business as usual; (2) Market forces; (3) Conservative development; (4) Innovation power.

[Figure 2 near here]

Generally speaking, scenarios are meant to outline qualitatively different directions of how the industry might evolve in the future, based on different sets of assumptions of their driving forces. In other words, potential consequences of these drivers, policy actions and tipping points are to be revealed in order to improve decisions. From the modelling perspective, these qualitative assumptions are turned into the values of parameters for model simulations. However, it is worth noting here again, that the simulation outcomes are not intended to predict the future, but rather explore the system's behavior in the context of different plausible futures on the horizon in 2045 to shed light on the transformation of the Russian construction sector. Utilization of the developed SD model for these four innovation futures is presented in Section 5. 
The below brief description focuses on the hypothetical estimates of the relative magnitude of change that could occur under each scenario to make the distinction between them.

\section{'Business as usual' scenario}

In this scenario, industry development and growth occur at a rate similar to today's. Namely, incremental performance improvements and innovation processes are hindered by tight financial situation, limited incentive schemes, outdated legislation, excessive administrative barriers and inappropriate technical regulation; financing for necessary R\&D is restricted and scientific and human potential is scarce. For the time being, coordination of construction procedures, time, and cost, are considered to be the primary problems of the Russian construction sector. Mainly it is due to the culture of 'lowest bid' that forces contractors to focus on initial cost, but not on the life-cycle costs and the value of design, on order to win a tender (Suprun and Stewart 2015).

\section{'Market forces' scenario}

In this scenario, innovativeness is mostly market-led and competition-driven under tight financial conditions. As a main client, government can significantly motivate decision-makers at construction firms to consider higher investment in innovation with driving demand for pathbreaking processes and products (e.g. through procurement and tender policies) (Eriksson 2017; Eriksson et al. 2017). In the current purchasing practices, clients give preference to a low cost over high quality and productivity, accompanied by fixed price payments that reduce contractors' incentives to innovate. By following the multi-criteria tender evaluation procedure, construction companies are required to meet a range of criteria, such as overall projects' wholelife value, safety, and quality, to name a few. However, financing for incentive schemes and science is restricted. 


\section{'Conservative development' scenario}

Government is in control of the industry development in this scenario. National targets have a high impact on the policy setting process aiming to increase the attractiveness of innovation implementation. The high rate of public investments, emphasis on incentive mechanisms and improvement of regulations, standards and legislation stimulate innovation diffusion. Nevertheless, the industry is still cost-competitive. Only well-established leading organizations can support R\&D, i.e. only those who can pay for it can be truly innovative. Thus, despite government's efforts to enhance innovativeness through additional investments, firms prefer to stay conservative and choose an imitative strategy which is far less costly and labor intensive.

\section{'Innovation power' scenario}

In this scenario the government drives and supports change by enforcing sustainable regulations and heavily investing in innovative infrastructure. At the same time, alternative procurement and tendering processes that aim to promote performance-based integrated delivery, induce companies to generate radical changes in creating know-how ideas; to invest a lot in R\&D; to develop a variety of solutions in order to keep up with high demand for innovative products and processes. As a result, rising competition reinforces the pressure to invest more in cutting-edge ideas and R\&D for a more competitive outlook. Overall, a strong will of both government and industry is necessary to ensure a successful transition.

\section{SD model formulation and evaluation}

\section{System boundary and key model elements}

The intended systems model was first designed in a form of a causal loop diagram (Suprun et al. 2018). Two core linked dynamic hypotheses describing the problem under investigation 
were revealed: (1) industry, government and academia should collaborate in order to accumulate innovative capabilities and support the development of innovation; (2) all the actors should cooperate to most effectively diffuse a stock of already known innovations throughout the industry. Then, an SD model was developed to express the innovation performance of the construction innovation system in Russia. The model is focused on the investigation of technological (i.e. product and process) innovations as they make up $70 \%$ of the total implemented innovations within the Russian construction industry (RSCI 2017; Gorodnikova et al. 2018). Product innovations include the use of new building materials, machinery and engineering equipment that increase operational and consumer qualities (e.g. energy-efficient, soundproofing materials). Process innovations include the introduction of new efficient construction technologies and software for architectural and construction design that allow the achievement of higher productivity, lower construction times, and so on (e.g. BIM, off-site fabrication). According to the study previously conducted by the authors (Suprun and Stewart 2015), the proportion of construction companies implementing technological innovations is less than $3 \%$ of the total market size compared to other sectors of Russia's economy such as energy $(22 \%)$ and biomedical (29\%) industries.

The duration of the analysis is from 2015 to 2045. In 2015 the Russian government set national targets to facilitate innovative development of the industry by designing an 'Innovative development strategy for the construction industry in Russia for the period up to 2030' (RSCI 2015). Initially, it was expected to achieve a ten-fold increase in the proportion of innovative construction companies by 2030 . However, the strategy was readjusted in 2017 showing a new trend (RSCI 2017). According to the new forecast, the level of technological innovation is planned to be tripled by 2030 . This adjustment proves the abovementioned complication of the innovation processes in the construction sector. Undoubtedly, a number of systematically targeted strategies and rational policies are required in order to achieve the set of government 
goals and shape successful transition of the construction sector in the innovative future. Hence, it was chosen to set the model time bound at 30 years to explicitly capture the long-term impact of various government policies on construction innovation performance.

Taking into account the emerged dynamic hypotheses, the model distinguishes between two types of innovative companies: imitators and innovators (Orstavik et al. 2015; Yusof et al. 2017). Imitators represent construction firms that introduce and implement technological innovations by adopting ideas from others and slightly improving construction materials, techniques, technologically advanced production methods, products and services. Such firms mainly implement innovations known as incremental, i.e. innovations that are new to a company, but not new to the market. Innovators represent companies that implement technological innovations as a result of collaborative R\&D. Such companies are constantly involved in R\&D and implement newly introduced (i.e. subjected to significant technological changes) construction materials, techniques, goods, and services based on new (including fundamentally new) technologies or on the combination of new technologies with existing ones. Considered as radical, these innovations are new or significantly different from those inherent in earlier products in the case of: field of application, performance characteristics, features, and design performance. Therefore, the model is composed of two main parts: imitators dynamics and innovators dynamics (Figure 3). The model was developed in Vensim software (Vensim DSS 2018).

[Figure 3 near here]

Rectangles represent stock variables, pipes with valves introduce flow variables, i.e. they represent those activities which fill in or drain the stock variables. Non-highlighted elements are auxiliary and constant variables, i.e. model parameters that are used for calculations and constructs that are dependent on stocks, flows, and/or other variables. The simple arrows indicate the cause-and-effect relationships within the model structure. Arrows 
labelled ' + ' point out causal influences that cause changes to an influenced variable in the same direction, whilst '-' labels dictate changes in the opposite direction. The double lines across the arrows are a delay symbol which indicates that an effect would take longer to appear. Emphasized purple variables are the main model outcomes. It is noted that the representation of the SFD is simplified in this paper, and only main variables and parameters are presented.

As mentioned previously, both rate of imitation and rate of innovation (i.e. imitators change rate and innovators change rate, respectively) are highly dependent on the pressure to innovate and industry innovative capability. In the model imitators capability is represented by the industry absorptive capacity, i.e. an ability of construction companies to identify, accumulate and exploit knowledge and technological opportunities of the sector in order to transfer and absorb cutting-edge technology, knowledge and skills (Gann 2001; Lim et al. 2006). Innovators capability consists of the industry absorptive capacity and $R \& D$ capacity, i.e. accumulated R\&D knowledge and efforts of the industry along with research centers and universities resulting in extra knowledge for significant improvement and development of the construction industry (Hampson et al. 2014). In order for the capabilities to be developed, firms must invest in innovative solutions in order to absorb any of the cutting-edge output of their competitors as well as the knowledge generated in the government institutions and universities. In the model, this dynamics is captured by industry resources for innovation funding variable, i.e. resources devoted to the development of industry innovative capabilities, technical competencies and innovation infrastructure.

Previously conducted studies show that there are three main factors that influence willingness of companies to invest more or less in innovative ideas: government support, administrative barriers and business performance. Hence, we developed an 'Attractiveness of being innovative' abstract term in collaboration with stakeholders. It is modelled as an aggregated index which takes normalized values between 0 and 1. Thus, 0 implies there is no 
attractiveness of implementing innovations at all, whereas 1 means a very high interest of companies in being involved in innovation processes. All three of the index components also have values of 0 to 1 . The normalization procedure is based on the literature (Seaden and Manseau 2001; Expert 2007; HSE 2013; Best and Meikle 2015; Suprun and Stewart 2015; Eriksson and Szentes 2017; Ozorhon and Oral 2017), government reports (RSCI 2015, 2017) and stakeholder workshops. In the SD model, values were assigned as presented in Appendix A.

System boundary, input data and assumptions as well as initial values for the key variables of the SD model are given in Appendix B. Units of measurement and the sources of data are also provided.

The base case scenario represents business as usual (BAU) conditions, i.e. the continuation of current trends in the Russian construction sector. The base run was calibrated through sensitivity analyses and qualitative analysis in collaboration with stakeholders to reach

relevant numbers and generate behaviors consistent with reality. As a result, missing or unavailable data for the initial value of some parameters (such as industry absorptive capacity) were estimated based on the calibration of model parameters.

\section{Model equations}

As mentioned previously, the SFD is a graphical representation of the mathematical model. Selected formulations related to the key model variables are presented below. The main target of the SD model is to show the behavior of construction companies implementing technological innovations over time. Industry innovative activity measured as the percentage of enterprises involved in innovation processes is considered to be one of the key indicators for measuring the innovative performance of the industry:

$I A(t)=\frac{\operatorname{Im}(t)+\operatorname{In}(t)}{C C(t)}$ 
where $I A$ is the industry innovative activity at time $t$; Im is number of imitators; $I n$ is number of innovators; and $C C$ is a total number of construction companies operating in the market.

Furthermore, the ratio between companies conducting R\&D activities and companies adopting innovations from others is another variable to track the dynamics of:

$I_{\text {ratio }}(t)=\frac{\operatorname{In}(t)}{\operatorname{Im}(t)+\operatorname{In}(t)}$

The total Attractiveness of being innovative index $A_{T}$ is presented as a stock that captures the impact of the following factors that influence the industry's decision to consider higher investments in innovation: level of government support, level of administrative barriers, and business performance of the industry. This stock can vary between 0 (lowest level = no attractiveness) and 1 (highest level = a nearly maximum interest of the industry to be involved in innovative processes for that moment in time). The stock accumulated at time $t$ is the sum of the Attractiveness of being innovative index in the previous period, plus new attractiveness $n A_{T}$ appearing as a result of change of the three factors noted above:

$$
\begin{aligned}
& A_{T}(t)=A_{T}\left(t_{0}\right)+\int_{t_{0}}^{t} n A_{T}(s) d s \\
& n A_{T}(t)=\left(\left(\left(\delta \cdot A_{A B}(t)+\beta \cdot A_{G S}(t)+\gamma \cdot A_{B P}(t)\right)-A_{T}(t)\right) / a\right.
\end{aligned}
$$

where $A_{A B}$ is attractiveness calculated as a function of the level of administrative barriers to innovation (Eq. 4); $A_{G S}$ is attractiveness calculated as a function of the level of government support (Eq. 5); and $A_{B P}$ is attractiveness calculated as a function of the industry's business performance (Eq. 6). The parameters $\delta, \beta$ and $\gamma$ denote the impact each of the above three elements makes on the willingness of industrialists to introduce novel solutions and technologies, with $\delta+\beta+\gamma=1$. These parameters were calculated based on the previously conducted structural analysis with MICMAC (for more details, please refer to Suprun et al. (2018)). Eq. 3.2 also points out that there is a lag between the actions taken by the government, 
construction companies or research institutes and their consequences resulting in a change in the attractiveness level. Thus, parameter $a$ indicates time needed for construction companies to consider following an innovative path as a result of active government involvement in innovation processes, high business performance and a reduced administrative and regulatory burden. According to the government reports (RSCI 2015, 2017) and expert judgment, $a$ equals two years.

$$
\begin{aligned}
& A_{A B}(t)=f(A B(t)) \\
& A_{G S}(t)=f(G S(t)) \\
& A_{B P}(t)=f(B P(t))
\end{aligned}
$$

The component attractiveness from administrative barriers $\left(A_{A B}\right)$ represents the industry's willingness to be innovative given the current state of building codes and standards, government contracts with inflexible fixed budgets, and so forth (Eq. 4). High levels of administrative barriers have a negative impact on the attractiveness of being innovative level, in the sense of higher values on this variable will make the attractiveness level closer to the minimum value (zero). We modelled this relationship by introducing a so-called lookup function that is used by modelers to specify non-linear relationships between a pair of variables (Sterman 2000). In order to identify the influence of administrative barriers and two other factors explained below on innovation attractiveness, experts were asked to create a graphic description of the relationship between the variables. This relationship is depicted in Figure 4a. As can be seen, this relationship follows an exponential decay behavior created by a reinforcing loop, where the increasing rate of change in attractiveness leads to the reduction in barriers.

[Figure 4 near here]

In contrast, innovations become more desirable for companies as a result of increasing government support. Hence, the component attractiveness from government support $\left(A_{G S}\right)$ represents the industry's willingness to be involved in innovation processes given the current 
state of public policies and incentive schemes, for example (Eq. 5). Subsequently, a higher level of government support contributes positively to the innovation development and diffusion. The relationship between attractiveness and government support is defined by a goal seeking behavior arising from a balancing loop (Figure $4 \mathrm{~b}$ ). In other words, industrialists tend to consider implementation of path-breaking processes and products when the government is trying to provide more financial support and incentivize the industry and academia. However, as discussed with the experts, by achieving a threshold of $100 \%(1.0)$ innovation attractiveness, companies may be able to invest in innovation themselves after a certain level of government funding and incentives have been provided.

Eventually, the component attractiveness from industry business performance $\left(A_{B P}\right)$ represents the companies' perception on the importance of innovation to their business development that changes as the result of change within company's profitability, productivity and client satisfaction as ones of the strongest motivational forces (Eq. 6). The attractiveness level rises rapidly after an initial slow growth but then gradually slows until the state of the system achieves a threshold of $100 \%$ (1.0). Graphically, this relationship is presented as an Sshaped growth curve (Figure 4c).

Attractiveness of innovation impacts decisions of companies regarding higher investments in innovative solutions. Innovation intensity indicates the amount of such investments:

$R(t)=I I(t) \times T(t)$

where $R$ is industry resources for innovation funding; $T$ is sector turnover (i.e. total of all sales (excluding VAT) of goods and services carried out by construction companies annually); and $I I$ is innovation intensity (Eq.8.1).

$$
\begin{aligned}
& I I(t)=I I\left(t_{0}\right)+\int_{t_{0}}^{t} n I I(s) d s \\
& n I I(t)=\left(\left(I I_{D}(t)-I I(t)\right) \times\left(A_{T}(t)-A_{T}\left(t_{0}\right)\right)^{i}\right) / b
\end{aligned}
$$


where $n I I$ denotes the new innovation intensity appearing as a result of change of attractiveness of being innovative $A_{T}$ at time $t$ in comparison to the initial value $A_{T}\left(t_{0}\right) ; I I_{D}$ is desired share of sector turnover on investment in innovation (following the government targets (RSCI 2015, 2017) and information regarding the average investment of construction companies in innovative solutions as a share of the total sector turnover in other countries, this parameter is set up at 0.02$) ; i$ represents the impact of attractiveness factors on innovation intensity (in the model this value was calibrated with sensitivity analysis where the results of innovation intensity were discussed with stakeholders). Eq. 8.2 also points out that there is a time lag between decision making and the actual mobilization of resources. Thus, parameter $b$ indicates the time needed for construction companies to allocate financial resources. According to expert judgment, $b$ equals one year.

Another variable considered to be one of the KPIs that assess innovation performance of the construction industry is $R \& D$ intensity:

$R D I(t)=\frac{\left(R D_{G}(t)+R D_{I}(t)\right)}{G D P_{C}(t)}$

where $R D_{G}$ is government funding for R\&D (i.e. funding to support fundamental and applied R\&D, particularly through R\&D collaboration practices between public-sector research organisations and the construction industry); $R D_{I}$ is industry R\&D funding; and $G D P_{C}$ is GDP from construction (i.e. gross value added (GVA) by the construction sector).

\section{Model evaluation}

In the field of system dynamics, a wide variety of tests, which are both qualitative and quantitative, has been developed to improve models (Barlas 1996). In fact, evaluation (calibration/validation) of a model is one of the key steps of the SD modelling procedure. It allows modelers to establish confidence in the structure, soundness and usefulness of a model before it can be used for decision making and policy analysis. However, there is no single way 
to validate a model, given the variety of objectives and criteria for different tests. For example, according to Sojda (2007), model evaluation consists of five main steps: (1) testing the system performance against preselected standards; (2) comparing simulated outputs with real-time and historic data; (3) expert judgments; (4) sensitivity analysis; (5) examining key parameters if the validation of a complete system is impossible.

Nevertheless, according to the founder of system dynamics, Jay Forrester, a model cannot be expected to have absolute validity (Forrester 1961). Sterman (2000) also agrees that all models are wrong, since they are simplified versions of reality. However, this does not mean that all models are useless as long as models can be judged and tested as truthful. If the model's representation of the real world shows plausible results, then modelers can gain more confidence about the model along with a deeper understanding of the system at hand (Sahin et al. 2018a).

Considering the specifics of this research, lack of empirical data, highly qualitative nature of the modelled system, participatory nature of the implemented modelling approach, and the fact that there is no exact algorithm for testing models, we followed a model evaluation process in which, modelers communicate the base for confidence in a model to stakeholders. The steps this study implemented to evaluate the model are as follows:

(1) Engaging stakeholders throughout the modelling process via stakeholder workshops and expert consultations in order to achieve an agreed final model and make sure the descriptive story behind the studied problem fit the model.

(2) Examining model parameters to check whether they had real world equivalents, and if not whether they were acceptable and acknowledged in theory. For example, it is hard to measure qualitative variables such as level of government support or innovative capability. However, those terms exist in the literature, are often used and can be 
normalized. Hence, the validity of the model from a parameter perspective was sufficient.

(3) Sensitivity analysis was performed to calibrate key input parameters and determine the importance of certain assumptions in order to generate a range of possible outcomes.

(4) Testing if the model confirmed the system boundary and the model behavior was consistent with the real world. Experts were involved in the evaluation process to ensure the model outputs adequately reflected the real situation by adjusting the modelling logic.

(5) Testing if the model behaved realistically under extreme conditions. If the model behaves as expected under such conditions, then it is possible to conclude that the model is robust and therefore behaves realistically under optimum conditions. For example, we assume that if there is no government support (i.e. 0 over the entire time horizon) and insurmountable administrative barriers (i.e. 1 over the entire time horizon), the level of innovation attractiveness will be extremely low. This leads to insufficient funding of innovation processes by the industry and, as a result, a very low level of innovative activity. Another extreme condition that might occur in the industry is GDP decline, leading to a serious decrease in the number of construction companies in general, and in number of innovative companies, in particular. We tested a scenario when GDP annual growth rate variable equals -0.05. As an example, Figure 5 illustrates the result of these experiments for two of the assessed variables. As can be seen in Figure 5a, the industry innovative activity keeps slightly increasing even when a country is experiencing a crisis situation resulting in significant GDP drop, which is unrealistic. However, by assessing Figure 5b, it becomes evident that the actual number of innovative companies drops gradually following the overall reduction in the number of construction companies operating on the market. In other words, the 
fraction of innovative companies might still rise, whilst it declines in equivalent measurement scale. Hence, the results showed that the model behaved realistically under extreme conditions.

[Figure 5 near here]

\section{Results and discussion}

\section{Scenario analysis}

Four scenarios were considered for the simulations to reveal insights about the construction innovation performance along with future transition pathways. The base case scenario represents business as usual (BAU). Outcomes arising from simulations of the other three alternative scenarios are compared to the baseline scenario in which no policy interventions applied. The experimental design is shown in Table 1. Assumptions regarding the values for a set of parameters were made based on the narrative description of the scenarios (Section 3) and stakeholder workshops. For the initial values of the base run and variables explanation, refer to Appendix B.

[Table 1 near here]

We estimated the implications of the aforementioned scenarios and policy assumptions for a 30-year time period, from 2015 to 2045 . The impacts in changes of key parameters on the dynamic behavior of the outcome variables, were studied in every simulation run. The following outcome variables were reported to compare the construction innovation performance across the scenarios: industry innovative activity, ratio between innovators and imitators, Attractiveness of being innovative index, innovation intensity and R\&D intensity. 
Figures 6 and 7 present the simulated results of innovative activity of construction companies, across four scenarios until 2045. In particular, Figure 6 illustrates the future growth trend for a number of innovative firms accompanied by the distribution between innovators and imitators. Fractions indicate ratio between innovators and imitators, measured as a proportion of innovators in the total amount of innovative construction companies which include both innovators and imitators. Figure 7 shows the level of industry innovative activity as a proportion of companies that implement technological innovations.

[Figure 6 near here]

[Figure 7 near here]

The industry grows steadily but very slowly under the BAU scenario, with no visible improvement in its innovative performance over time. In contrast, the innovative activity shows faster dynamics under MF and CD scenarios. Yet, this happens after almost a decade of the simulation horizon. It explains the necessity to accumulate enough capabilities to not only be involved in innovative projects successfully but also to encourage industrialists to consider investments in innovations in the long-run. Finally, under the IP scenario the sector grows rapidly up until 2040 and then slows down by reaching its steady state level of $12.5 \%$ by 2045 , which is twice as high as in the BAU simulation (5.8\%). It corroborates the main assumption of the scenario, i.e. priority in promoting $R \& D$, investing more in cutting-edge ideas and eventually transforming the sector into a high-tech sector that is capable of supporting science and research. Even though the fraction of innovators almost equals the fraction of imitators in this scenario ( 0.45 and 0.55 , respectively), it is apparent from the figures, in the simulated state of the construction sector in 2045 , the industry will remain imitation-oriented under any circumstance. Moreover, under a market-driven scenario, companies give priority to maintaining the competitive advantage by trying to improve their absorptive capacity, i.e. 
investing primarily in new equipment and providing training to their personnel, but not collaborating with universities and research centers to develop new solutions. Thus, only $31 \%$ (approximately 16,000 firms) of innovative companies are innovators, which is even lower than those in the reference case. In other words, the mechanism of learning-by-using supersedes learning-by-searching, i.e. innovations are well diffused within the industry but developed to a very limited extent. It is consistent with the fact that the Russian economy is unprepared for the market-led regime to be able to compete worldwide (TASS 2014; RSCI 2017). Therefore, this finding can be interpreted as the necessity to consider significant government support of the industry and academia in order to improve domestic R\&D and science, in addition to policies targeting the growth of the construction industry itself. However, as can be seen in Figures 6 and 7, providing financial incentives to boost innovative processes under the $\mathrm{CD}$ scenario is still not going to lead to the same results as when successful incentive schemes are accompanied by quality competitiveness driving the market.

Industry innovative activity plays a central role in analyzing the effectiveness of innovation policies, hence we studied the dynamic behavior of this variable in more detail by running a sensitivity analysis (Figure 8). In general, a sensitivity analysis is performed to determine the importance of certain assumptions and to generate a range of possible outcomes. The resulting scenarios can then suggest how the 'desired future' process might be achieved. As can be seen in Figure 8, the IP scenario is the best out of four tested scenarios, but not 'perfect'. The maximum proportion of total construction companies that might be potentially obtained is $15 \%$ which is consistent with the maximum innovative activity the sector has a capacity for. Our model limited the number of potential innovative companies to a number of large and medium-sized construction firms. The fraction of such companies is around $15 \%$. However, such 'ideal' outcomes seem unlikely to be achieved in a real-world situation. Consequently, it can be concluded again that the model provides plausible outcomes. 
[Figure 8 near here]

Attractiveness of being innovative

Figure 9 shows how the effectiveness of government policies affects the level of government support, level of administrative barriers, business performance of construction companies, and as a result, attractiveness of innovation, overall. All elements vary between 0 and 1 . We assume that the Russian government will not change the direction of the construction industry towards an innovative pathway within the BAU scenario. Hence, the level of government support stays 'poor' (refer to the scale given in Appendix A for description) over the entire simulation horizon, while the level of administrative barriers remains 'insurmountable'. As a result, the attractiveness level will only reach 0.19 by 2045 compared to 0.15 at the beginning of simulation. It rises due to the slight growth in business performance resulting from the slow but steady innovation implementation leading to some improvements in the quality of construction and productivity experienced only by innovation champions. In contrast, the speeding effect of government financial incentives accompanied by rising demand for research and innovation through regulatory frameworks, procurement schemes and tender procedures (i.e. a complex of measures) is reflected in the Attractiveness of being innovative index under the IP scenario.

[Figure 9 near here]

The index almost reaches the highest level of 1 by 2045, which means that construction companies shift from a short-term business thinking attitude to acknowledgement that innovation implementation has to be a priority for improving the efficiency and effectiveness of the industry. Hence, decision-makers consider higher investments in innovation that lead to the use of innovative materials and technology enabling companies to improve the quality of their products and services, reduce cost and time of construction works, enter new markets, and satisfy high expectations of customers. In other words, an increase of the industry business 
performance becomes evident. It is in this sense that the accumulation of innovation attractiveness in the system is caught up in a vicious cycle.

Nevertheless, it is difficult to achieve a radical change of the industry at a national level. Even a slight change of the parameter settings related to the effectiveness of the government strategies lead to noticeably different outcomes. For example, we observe a significant improvement in industry business performance under the MF scenario, however administrative barriers remain excessive, i.e. bureaucracy and regulations are difficult and slow to improve without targeted government actions. Additionally, the state of government support only reaches an adequate level by 2045 , indicating non-systematic individual improvements in terms of various incentive mechanisms to support technological modernization of the industry, while providing conditions for increasing demand for innovative products. Simulations under the CD scenario provide better outcomes in terms of strengthening government support and reducing administrative barriers. However, interestingly, the industry performs better in terms of business outcomes up until 2035 under the MF scenario, which is the indication of high competition in the market that forces decision-makers at construction firms to consider innovation implementation to stay afloat. An active imitative strategy among industrialists requires less effort to build a certain level of innovative capability necessary to adapt technology and production processes. As a result, firms evolve in innovation processes and achieve desirable results faster. However, business performance under the CD scenario surpasses the MF scenario outcome after 2035 and continues to increase gradually. This situation illustrates why firms are encouraged to invest in $R \& D$ to achieve better results in the long-run.

\section{Innovation intensity and $R \& D$ intensity}

In terms of innovation and R\&D intensity, four scenario outcomes demonstrate considerable differences, as shown in Figure 10. 
[Figure 10 near here]

Under the BAU scenario, R\&D intensity remains scanty over the simulation horizon while the increase in industry innovation intensity can be seen only after 2030 , yet this is a slight change. In other words, the innovation system does not develop sufficient innovative capability. Relatively, the improvement in the MF scenario compared with the reference case is quite small in terms of the pace of R\&D processes which is hindered by tight funding conditions. In contrast, the scenario demonstrates a significant growth of innovation intensity. It complements our argument on the future state of the construction innovation processes under the MF scenario, i.e. the preference of construction companies to adopt innovative solutions over $\mathrm{R} \& \mathrm{D}$ in the long-run due to less cost and labor intensity and rather good implementation outcomes. The IP scenario is the one that is able to achieve rapid development by means of a dynamic R\&D sector and a high level of innovation attractiveness among industrialists. As can be seen in Figure 10, both innovation and R\&D intensity accelerate, up until 2035 and then slow down. It is worth noting, that innovation intensity's value saturates by reaching the desired level of $2 \%$ by 2045 . Meanwhile, it becomes evident that the realization of the government strategy to spend more than $1.8 \%$ of GDP on R\&D is not easy to achieve, and does not occur even under the IP scenario. This means that the coordination of the innovation system's actors requires more support to meet those targets in the longer run. Moreover, considering the scenario features, a firm that faces high business performance standards, but operates in a system of innovation with low R\&D capabilities, is at a higher risk to go out of business than if the same firm recognizes the importance of investments in R\&D and interacts actively with academia. Finally, the CD scenario results demonstrate that the high level of innovation diffusion is driven by imitators, since the graph shows research passivity of the industry as R\&D intensity grows over time but stays on a lower trajectory for a long period. Considering the absence of the direct demand for R\&D products, this outcome can be interpreted as a 
necessity to support financial incentives of research organizations in order to obtain a higher R\&D knowledge stock in the long-term.

\section{Policy recommendations}

Based on the transition pathway scenario analysis conducted in this study, a number of opportunities and threats were identified for each of the four scenarios (Table 2).

[Table 2 near here]

It can be concluded that the public sector plays a pivotal role in each of the scenarios. The current state of innovation processes undeniably calls on the government to remove barriers to innovative procurement and to provide innovation incentives, even in the market-driven scenario. A number of recommendations for the industry transition into alternative innovative futures is provided below.

The Market forces transition pathway scenario includes improvement in procurement practices leading to increasing demand for high-quality construction products and goods, within the constraints of a competitive market economy framework. If this is the preferred or likely transition pathway, the following actions should be taken to aid its fulfilment:

- Procurement modes should be significantly modified to embrace innovation. Specifically, public procurement should specify increased level of innovation in terms of design (e.g. Building information modelling), construction (e.g. modular construction), and life cycle asset performance (e.g. green building).

- Regulatory frameworks must concentrate on targeted performance outputs and not only on particular technologies that need to be implemented.

- Absorption of available on the market innovations and increase in technological opportunities of the sector are only possible when training in the use of new 
technologies, machinery, processes and materials is provided. Given the limited direct public financial support for this scenario, government should focus on upskilling tertiary providers.

- New business models are needed to heighten focus on value creation instead of costcutting. Ensuring that multi-criteria tender selection criteria include items related to innovative construction approaches, as well as greater focus on safety, environmental and quality.

The Conservative development transition pathway scenario involves greater investment in innovation than the BAU scenario but the current restrictive market environment is still predominant. If this is the preferred or likely transition pathway, the following actions should be taken to aid its fulfilment:

- The public sector has to be coherent and organized as it is the dominant investor. Additional construction costs associated with innovations will need to be subsidized through economic incentives such as grants, awards, funds and recognition programs. Moreover, funding and incentive schemes for research projects have to be available. Government funding could be scaled back over time as innovative maturity evolves.

- A greater level of cooperation between the government, designers, contractors and researchers is essential to overcome barriers associated with uncertainties of using innovative ideas. Hence, policy frameworks need to be focused on promotion of stronger engagement of the industry with academia to: overcome shortages of skills; facilitate increased knowledge transfer and learning into the industry; and to enable applied R\&D with the intention of bridging the gap between a novel concept and a commercialized construction product or service. 
- It is necessary to support the ongoing evolution of building codes and standards as a means to push innovation implementation. In particular, national building codes need to be harmonized with Eurocodes, which are more supportive of novel design and construction approaches.

In the Innovation power transition pathway scenario, construction companies and academia are incentivized financially to work together, and innovation is encouraged through a competitive market environment. The following actions are recommended to achieve the desired goals of this preferred transition pathway:

- The scenario requires industry-wide commitment to collaboration and investment as well as sustained government support of a competitive market economy.

- Government needs to introduce appropriate incentives and rewards to encourage an 'innovation mind-set' among all members of the innovation process, and foster a culture of learning. First of all, such incentive mechanisms facilitate industry's collaboration with academia to transform basic research to industrial prototypes, and ultimately strategic commercialized application. Such networks allow greater integration and financial stability of companies as they benefit from the value created by sharing R\&D.

- Overall, strong public and private spending on construction-related R\&D should take place.

- Identification and dissemination of successful innovation exemplars is needed, so companies may respond effectively to emerging opportunities associated with business benefits, as well as challenges arising from innovations.

- National codes should be replaced with Eurocodes. It would allow the industry to adopt novel design approaches and address important energy and environmental aspects. 
- It is necessary to introduce tools of data analysis to inform all members of the construction process on the importance of considering life-time-performance, long-term functionality, and the life-cycle cost of a construction asset.

It is worth noting, that the majority of the presented policies within each of the transition pathways interrelate with the economic, institutional and social environment. For this reason, transformation of the industry is difficult and time-consuming, requiring simultaneously radical changes in the mind-sets of all actors of the construction innovation system.

\section{Conclusions and future research directions}

Effective strategies are required to overcome the challenges of transforming Russia's construction industry into one which is progressive and innovative. Nevertheless, innovation is only likely to occur if there is sufficient support for increased collaboration within the innovation system and research into new materials and technologies. In this paper, an SD model was developed as part of the IPSM approach to provide understanding on how construction innovation would evolve in the context of four plausible transition pathway scenarios of the Russian construction industry. Specifically, the research sought to explicitly capture the impact of various government policies, provide deeper understanding of how construction companies would behave in the context of different plausible 'futures', and enable decision makers to design rational policies to improve the chances of better futures actually occurring.

Various stakeholders with diverse backgrounds were involved in the SD model development, calibration and testing processes. The complex multi-actor nature of the system under investigation justified the IPSM approach for modelling the innovation processes and studying dynamic behavior of the key parameters under different scenarios. The scenario analysis was performed with the notion of transition pathways to evaluate the possible futures of the Russian construction industry with regard to innovation development and diffusion. One 
key finding was that the Russian construction industry preferences imitation-oriented innovation development. The innovation power transition pathway does produce more truly innovative companies than the other scenarios, but even in this scenario it takes time to develop a sufficient proportion of them. Overall, simulation results under alternative scenario settings revealed that industry transformation requires sustained and coordinated innovation diffusion strategies that engages all innovation stakeholders. An important topic for future research would be to examine how the competitive dynamics between imitators and innovators depend on different circumstances. Additionally, future research should expand on the herein SD model to include specific indicators of company business performance that will improve with innovation (e.g. profitability, productivity, client satisfaction). Another direction would be to explore the impact of certain education and training strategies on the industry innovation performance, as instilling a 'culture of learning' is necessary for companies to keep up with the pace of change. The versatility of the SD model allows for refinements to be made and new modules to be included in order to investigate the aforementioned research topics.

\section{Acknowledgments}

The authors would like to thank participants of the stakeholder workshops and individuals that consulted the researchers throughout the modelling process. This research would not have been possible without their valuable insights and contribution.

\section{Disclosure statement}

No potential conflict of interest was reported by the authors.

\section{References}

Barlas Y. 1996. Formal aspects of model validity and validation in system dynamics. Syst Dynam Rev. 12(3):183-210. 
Berezina EV, Lebedev KV, Pluzhnova NA, Prokhorova LV, Fedin AV. 2017. Science and Education Statistics. Volume 6. R\&D Funding. Moscow: SRI FRCEC.

Best R, Meikle J. 2015. Best R, Meikle J, editors. Measuring Construction. London: Routledge.

Blayse AM, Manley K. 2004. Key influences on construction innovation. Construction Innovation: Information, Process, Management. 4(3):143-154.

Costanza R, Daly L, Fioramonti L, Giovannini E, Kubiszewski I, Mortensen LF, Pickett KE, Ragnarsdottir KV, De Vogli R, Wilkinson R. 2016. Modelling and measuring sustainable wellbeing in connection with the UN Sustainable Development Goals. Ecological Economics. 130:350-355.

Dangerfield B, Green S, Austin S. 2010. Understanding construction competitiveness: the contribution of system dynamics. Innov Built Envir. 10(4):408-420.

Dansoh A, Oteng D, Frimpong S. 2017. Innovation development and adoption in small construction firms in Ghana. Innov Built Envir. 17(4):511-535.

Davidson C. 2013. Innovation in construction - before the curtain goes up. Innov Built Envir. 13(4):344351.

Davis P, Gajendran T, Vaughan J, Owi T. 2016. Assessing construction innovation: theoretical and practical perspectives. Construction Economics and Building. 16(3):12.

Doing Business. 2018. Doing business in Russian Federation. The World Bank; [accessed 2018 January 20]. www.doingbusiness.org/data/exploreeconomies/russia/.

Egbu CO. 2004. Managing knowledge and intellectual capital for improved organizational innovations in the construction industry: An examination of critical success factors. Engineering, Construction and Architectural Management. 11(5):301-315.

Eriksson PE. 2017. Procurement strategies for enhancing exploration and exploitation in construction projects. Journal of Financial Management of Property and Construction. 22(2):211-230.

Eriksson PE, Larsson J, Pesämaa O. 2017. Managing complex projects in the infrastructure sector - A structural equation model for flexibility-focused project management. International Journal of Project Management. 35(8):1512-1523.

Eriksson PE, Szentes H. 2017. Managing the tensions between exploration and exploitation in large construction projects. Innov Built Envir. 17(4):492-510.

Etemadinia H, Tavakolan M. 2018. Using a hybrid system dynamics and interpretive structural modeling for risk analysis of design phase of the construction projects. International Journal of Construction Management.1-20.

Expert. 2007. Innovation in construction cluster: barriers and perspectives - survey report.

Farla J, Markard J, Raven R, Coenen L. 2012. Sustainability transitions in the making: A closer look at actors, strategies and resources. Technol Forecast Soc. 79(6):991-998.

Forecast. 2013. Long-Term Forecast for the Socioeconomic Development of the Russian Federation up to 2030. Moscow.

Forrester JW. 1961. Industrial Dynamics. Massachusetts Institute of Technology Press. 
FSSS. 2018. Russian Federation Federal State Statistics Service. [accessed 2018 January 20]. www.gks.ru/.

Gann D. 2001. Putting academic ideas into practice: technological progress and the absorptive capacity of construction organizations. Constr Manag Econ. 19(3):321-330.

Geels FW, Berkhout F, van Vuuren DP. 2016. Bridging analytical approaches for low-carbon transitions. Nature Climate Change. 6:576.

Gilkinson N, Dangerfield B. 2013. Some results from a system dynamics model of construction sector competitiveness. Mathematical and Computer Modelling. 57(9):2032-2043.

Gorodnikova N, Gokhberg L, Ditkovskiy K. 2018. Indicators of innovation in the Russian Federation: Data Book. Moscow: National Research University Higher School of Economics: HSE.

Grigoryev YV. 2011. Obstacles of innovative activity. Innovation Industrial Policy and Economics. 4(1):5-14.

Grobbelaar SS, Buys AJ. 2011. A conceptual systems dynamics model of research and development activities in South Africa. The South African Journal of Industrial Engineering 16(2):103-121.

Grösser SN. 2017. Complexity Management and System Dynamics Thinking. In: Grösser SN, ReyesLecuona A, Granholm G, editors. Dynamics of Long-Life Assets: From Technology Adaptation to Upgrading the Business Model. Cham: Springer International Publishing; p. 69-92.

Hampson K, Kraatz JA, Sanchez AX. 2014. R\&D Investment and Impact in the Global Construction Industry. Taylor \& Francis.

Han S, Lee S, Park M. 2014. Dynamic Project Management: An Application of System Dynamics in Construction Engineering and Management. In: Xu H, Wang X, editors. Optimization and Control Methods in Industrial Engineering and Construction. Dordrecht: Springer Netherlands; p. 219-231.

HSE. 2013. Innovative construction materials and technologies: their influence on the development of urban planning and urban environment. Moscow: National Research University Higher School of Economics: HSE.

Kubiszewski I, Costanza R, Anderson S, Sutton P. 2017. The future value of ecosystem services: Global scenarios and national implications. Ecosystem Services. 26:289-301.

Leon H, Osman H, Georgy M, Elsaid M. 2018. System Dynamics Approach for Forecasting Performance of Construction Projects. J Manage Eng. 34(1):04017049.

Li FGN, Trutnevyte E, Strachan N. 2015. A review of socio-technical energy transition (STET) models. Technol Forecast Soc. 100:290-305.

Lim JN, Ofori G, Ling FYY, Hua GB. 2007. Role of national institutions in promoting innovation by contractors in Singapore. Constr Manag Econ. 25(10):1021-1039.

Lim JN, Ofori G, Park M. 2006. Stimulating Construction Innovation in Singapore through the National System of Innovation. Journal of Construction Engineering and Management. 132(10):1069-1082.

Lim JN, Peltner F. 2011. Innovation performance of construction enterprises: An empirical assessment of the German and Singapore construction enterprises. Innov Built Envir. 11(3):282-304. 
Loosemore M. 2013. Innovation, Strategy and Risk in Construction: Turning Serendipity Into Capability. Taylor \& Francis.

Lundvall B-A. 1992. National Systems of Innovation. London: Pinter.

Maani KE, Cavana RY. 2007. Systems Thinking, System Dynamics: Managing Change and Complexity. Auckland, N.Z.: Prentice Hall.

Malerba F. 2002. Sectoral systems of innovation and production. Res Policy. 31(2):247-264. English.

Maryani A, Wignjosoebroto S, Partiwi SG. 2015. A System Dynamics Approach for Modeling Construction Accidents. Procedia Manufacturing. 4:392-401.

Moallemi EA, de Haan F, Kwakkel J, Aye L. 2017. Narrative-informed exploratory analysis of energy transition pathways: A case study of India's electricity sector. Energy Policy. 110:271-287.

Mohamed S, Chinda T. 2011. System dynamics modelling of construction safety culture. Engineering, Construction and Architectural Management. 18(3):266-281.

Montalvo C, van der Giessen A. 2011. Sectoral Innovation Watch - Synthesis Report. European Commission: (Europe INNOVA Sectoral Innovation Watch for DG Enterprise and Industry.

Morecroft JDW. 2008. Strategic Modelling and Business Dynamics: A Feedback System Approach. Chichester: Wiley.

Nasirzadeh F, Khanzadi M, Mir M. 2018. A hybrid simulation framework for modelling construction projects using agent-based modelling and system dynamics: an application to model construction workers' safety behavior. International Journal of Construction Management. 18(2):132-143.

Nelson RR. 1993. National Innovation Systems: A Comparative Analysis. Oxford University Press.

Orstavik F, Dainty ARJ, Abbott C. 2015. Construction Innovation. Wiley.

Ozorhon B. 2013. Analysis of Construction Innovation Process at Project Level. J Manage Eng. 29(4):455-463.

Ozorhon B, Abbott C, Aouad G, Powell J. 2010. Innovation in Construction: A Project Life-Cycle Approach. Salford: University of Salford.

Ozorhon B, Oral K. 2017. Drivers of Innovation in Construction Projects. Journal of Construction Engineering and Management. 143(4):04016118.

Panuwatwanich K, Stewart RA, Mohamed S. 2008. The role of climate for innovation in enhancing business performance. Engineering, Construction and Architectural Management. 15(5):407-422.

Panuwatwanich K, Stewart RA, Mohamed S. 2009a. Critical pathways to enhanced innovation diffusion and business performance in Australian design firms. Automat Constr. 18(6):790-797.

Panuwatwanich K, Stewart RA, Mohamed S. 2009b. Validation of an empirical model for innovation diffusion in Australian design firms. Construction Innovation: Information, Process, Management. 9(4):449-467.

RSCI. 2015. Innovative development strategy for the construction industry in Russia for the period up to 2030. Ministry of Construction, Housing and Utilities of the Russian Federation. Moscow. 
RSCI. 2017. Innovative development strategy for the construction industry in Russia for the period up to 2030. Ministry of Construction, Housing and Utilities of the Russian Federation. Moscow.

Sahin O, Bertone E, Beal C, Stewart RA. 2018a. Evaluating a novel tiered scarcity adjusted water budget and pricing structure using a holistic systems modelling approach. Journal of Environmental Management. 215:79-90.

Sahin O, Miller D, Mohamed S. 2018b. Value-based modelling: an Australian case of off-site manufactured buildings. International Journal of Construction Management. 18(1):34-52.

Samara E, Georgiadis P, Bakouros I. 2012. The impact of innovation policies on the performance of national innovation systems: A system dynamics analysis. Technovation. 32(11):624-638.

Seaden G, Manseau A. 2001. Public policy and construction innovation. Build Res Inf. 29(3):182-196.

Sojda RS. 2007. Empirical evaluation of decision support systems: Needs, definitions, potential methods, and an example pertaining to waterfowl management. Environmental Modelling \& Software. 22(2):269-277.

Sterman J. 2000. Business Dynamics: Systems Thinking and Modeling for a Complex World. Boston, MA: McGraw-Hill Education.

Stewart RA. 2007. IT enhanced project information management in construction: Pathways to improved performance and strategic competitiveness. Automat Constr. 16(4):511-517.

Suprun E, Sahin O, Stewart R, Panuwatwanich K. 2016. Model of the Russian Federation Construction Innovation System: An Integrated Participatory Systems Approach. Systems. 4(3):29.

Suprun E, Sahin O, Stewart R, Panuwatwanich K, Shcherbachenko Y. 2018. An Integrated Participatory Systems Modelling Approach: Application to Construction Innovation. Systems. 6(3):33.

Suprun E, Stewart R. 2015. Construction innovation diffusion in the Russian federation. Innov Built Envir. 15(3):278-312.

TASS. 2014. Sanctions as a way to support domestic producers. Russian news agency; [accessed 2014 December 1]. http://itar-tass.com/ekonomika/1379999.

Uriona Maldonado M, Grobbelaar SS. 2018. Innovation System Policy Analysis through System Dynamics Modelling: A Systematic Review. Science and Public Policy.1-17.

Uriona Maldonado M, Pietrobon R, Varvakis G, Carvalho E. 2012. A preliminary model of innovation systems. 30th International Conference of the System Dynamics Society; July; St. Gallen, Switzerland.

Van Egmond E. 2012. Innovation, Technology and Knowledge Transfer for Sustainable Construction. In: Akintoye A, Goulding, J.S., Zawdie, G., editor. Construction Innovation and Process Improvement. London, UK,: Wiley-Blackwell; p. 95-123.

Vensim DSS. 2018. Simulation software. Ventana Systems; [accessed]. http://vensim.com/download/.

Xue X, Zhang R, Yang R, Dai J. 2014. Innovation in construction: A critical review and future research. International Journal of Innovation Science. 6(2):111-126. 
Yusof NA, Kong Seng L, Kamal EM. 2017. Characteristics of innovation orientations in construction companies. Journal of Engineering, Design and Technology. 15(4):436-455.

Zou B, Guo F, Guo J. 2016. Absorptive capacity, technological innovation, and product life cycle: a system dynamics model [journal article]. SpringerPlus. 5(1):1662. 


\section{Appendix A. Qualitative scale for normalized variables}

Table A1. Qualitative scale for the variables impacting attractiveness of being innovative.

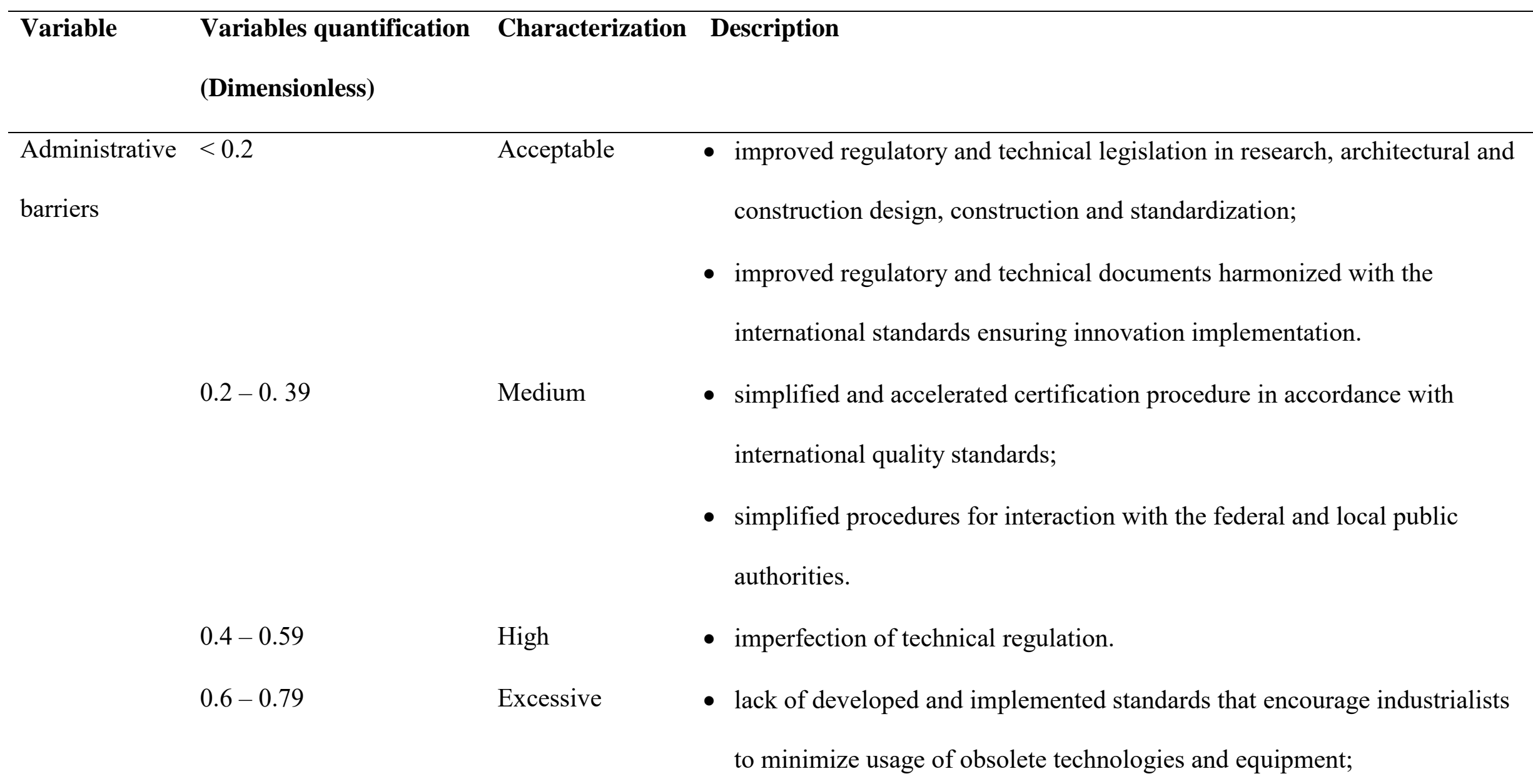


- incompatibility of construction norms, codes and rules with international standards.

$0.8-1$

Government

$<0.2$

support
Insurmountable

Insufficient

$0.4-0.59$
- outdated standards and other regulatory documents.

- lack of or very weak systemic public support and inadequate incentive measures to stimulate the construction sector and related industries (e.g. design, transportation, engineering, protection of natural resources, science, education).

- insufficient instruments of government support for innovative activities, i.e. limited flexibility and underdevelopment of mechanisms for allocating risks between the state and construction companies;

- weak focus on stimulating links between various actors in innovation processes, including research and production partnerships.

- development of various mechanisms to support technological modernization of the industry, while there are still only individual improvements, fragmentation and instability of the overall progress in this area remain; 
- stimulation of demand for innovative products;

- state control of enterprises that do not meet the requirements of energy and resource consumption along with the environmental safety.

$0.6-0.79$

$<0.2$

Industry

business

performance
$0.2-0.39$
Sufficient

- improved grant schemes for medium and large enterprises in the construction industry that implement innovative solutions;

- strengthening support for fundamental and applied research in universities and research centers followed by integrated scientific and educational activities;

- strengthening the export role of the Russian science.

High

- direct budget funding;

- subsidizing of an interest rate on loans for enterprises that produce and purchase innovative equipment.

- weak business performance in terms of low quality, high costs, very narrow profit margins and unsatisfied clients.

Unsatisfactory
- low quality-price ratio of the investments. 

$0.4-0.59$
Satisfactory
- a company's revenue is higher than the investment required for
$0.6-0.79$
Good development and implementation of innovation.
increased productivity and profitability as a result of application of innovative practices;
- completed projects meet specifications and clients' expectations.
$0.8-1 \quad$ Excellent
- desired performance in terms of superior quality and high client satisfaction;
- strong financial performance and profitability;
- arising opportunities to enter new markets.

\section{Appendix B. System boundary: Key variables and input data for the SD model.}

Table 1B. Key variables, assumptions and data for the SD model.

\begin{tabular}{lcll}
\hline Parameter & Value & Unit & Comments / Sources of data \\
\hline Imitators & 3154 & Firms & Calculated based on FSSS (2018) and Gorodnikova et al. (2018) \\
Innovators & 1553 & Firms & Calculated based on FSSS (2018) and Gorodnikova et al. (2018)
\end{tabular}




\begin{tabular}{|c|c|c|c|}
\hline $\begin{array}{l}\text { Proportion of large and medium } \\
\text { size construction firms }\end{array}$ & 0.152 & $\mathrm{Dmnl}^{\mathrm{a}}$ & FSSS (2018) \\
\hline Construction market size & 235,351 & Firms & FSSS (2018) \\
\hline GDP & $\begin{array}{l}83.387 \\
\text { trillion }^{\mathrm{b}}\end{array}$ & Rubles/Year & FSSS (2018) \\
\hline GDP annual growth rate & 0.03 & $\mathrm{Dmnl} /$ Year & Based on the government Forecast (2013) \\
\hline Construction contribution to GDP & 0.06 & Dmnl & Based on the government forecast (RSCI 2015, 2017) \\
\hline Pressure to innovate & $0.5^{\mathrm{c}}$ & Dmnl & $\begin{array}{l}\text { An abstract variable showing how companies are forced externally to consider } \\
\text { innovation implementation. The assumptions were made based on stakeholder } \\
\text { workshops and government reports (RSCI } 2015,2017 \text { ) }\end{array}$ \\
\hline Level of government support & $0.3^{\mathrm{c}}$ & Dmnl & $\begin{array}{l}\text { For the description refer to Appendix A. The assumptions were made based on } \\
\text { stakeholder workshops and government reports (RSCI 2015, 2017) }\end{array}$ \\
\hline $\begin{array}{l}\text { Level of administrative barriers to } \\
\text { innovation }\end{array}$ & $0.8^{\mathrm{c}}$ & Dmnl & $\begin{array}{l}\text { For the description refer to Appendix A. The assumptions were made based on } \\
\text { stakeholder workshops and government reports (RSCI 2015, 2017) }\end{array}$ \\
\hline $\begin{array}{l}\text { Business performance of } \\
\text { construction companies }\end{array}$ & $0.3^{\mathrm{c}}$ & Dmnl & $\begin{array}{l}\text { For the description refer to Appendix A. The assumptions were made based on } \\
\text { stakeholder workshops and government reports (RSCI 2015, 2017) }\end{array}$ \\
\hline
\end{tabular}


Government innovative strategy

0

Dmnl

This parameter is modelled as a switch variable, i.e. setting it to 0 or 1 allows

modelers to distinguish between non-strategy ${ }^{d}$ following pathway, where level of government support and administrative barriers do not change over the simulation horizon; and an innovative pathway, where the switched-on variable activates a number of dynamic parameters that indicate how efficient the government is in implementing the planned strategies and policies towards the development of successful and forward looking construction industry

Innovation intensity

Industry absorptive capacity

$0.001 \quad$ Dmnl

$0.2^{\mathrm{c}} \quad$ Dmnl

Industry R\&D capacity $0.05^{\mathrm{c}} \quad$ Dmnl
Calculated based on Gorodnikova et al. (2018)

An abstract variable showing the construction sector's ability to absorb existing knowledge and implement innovations. The assumptions were made based on stakeholder workshops

An abstract variable showing the accumulation of R\&D efforts of the industry with the research centers, universities and government, resulting in extra knowledge for significant improvement and development of construction innovation. The assumptions were made based on stakeholder workshops 
R\&D knowledge

Cost competitiveness

Model time bound

Physical boundary
Dmnl

An abstract variable representing the stock of available R\&D knowledge which is modelled based on several studies in knowledge management that applied system dynamics technique (Grobbelaar and Buys 2011; Uriona Maldonado et al. 2012; Zou et al. 2016). The parameter has no limit to growth.

Dmnl

This parameter is modelled as a switch variable, i.e. setting it to 1 or 0 allows

modelers to distinguish between the construction industry's low cost competitive strategy due to client demand for cost over quality that forces companies to focus on short-term fixes and produce low-cost but also low-quality infrastructure and building assets; and shift from cost-competition in current procurement practices to one that focuses on life-time-performance, where the switched-off variable activates a number of dynamic parameters that indicate how the industry reacts to the changing demand for innovative products.
30 years
From 2015 to 2045

Large and medium-sized construction companies implementing technological innovations in Russia.

Notes:

${ }^{\text {a }}$ Dmnl $=$ Dimensionless

${ }^{\mathrm{b}}$ Exchange rate for September 2018: 1.0 RUB = 0.015 USD

${ }^{c}$ Elements vary between 0 and 1

d Innovative development strategy for the construction industry in Russia for the period up to 2030 (RSCI 2015, 2017) 


\section{TABLES}

Table 1. Key scenario settings.

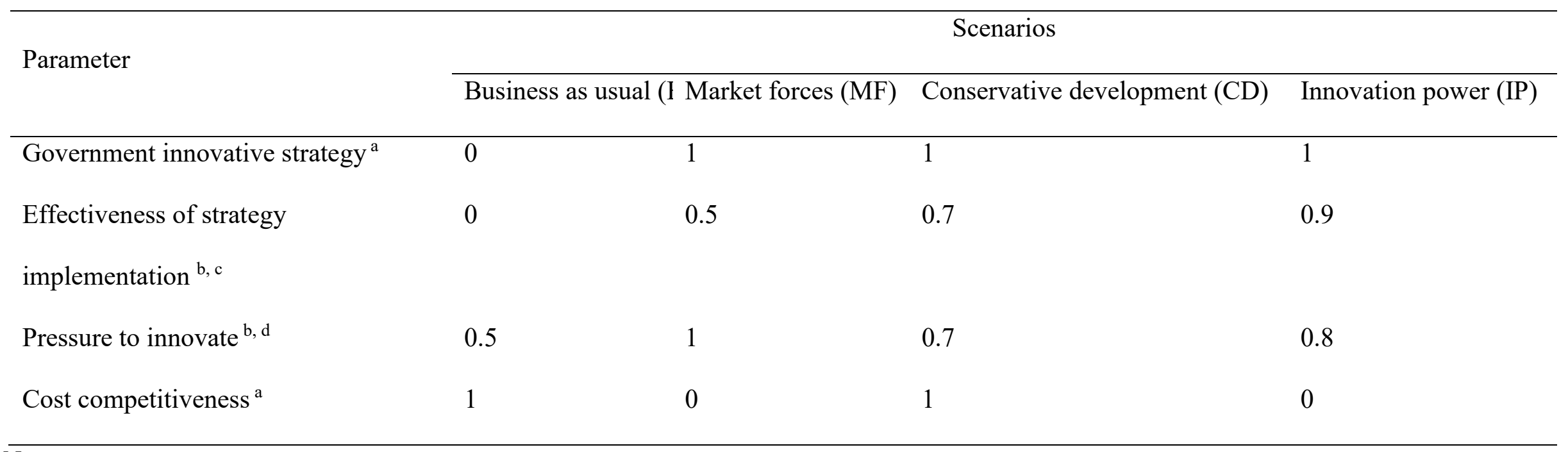

Notes:

${ }^{a}$ Refer to Appendix B for the values explanation

${ }^{\mathrm{b}}$ Elements vary between 0 and 1

${ }^{\mathrm{c}}$ This parameter indicates how efficient the government is in implementing the planned strategies and policies towards the development of the high-level innovation performance within the construction industry. Thus, 0 implies there is no action taken towards strengthening government support and reducing administrative barriers; whereas 1 means the government contributes to the implementation of effective policies towards stimulating higher levels of construction innovation as part of the overall country's development strategy to respond to future economic and social challenges. 
${ }^{d}$ This parameter shows how companies are forced externally to consider innovation implementation. The highest pressure appears under the MF scenario, i.e. the growing competition in the construction companies forces companies to have a stable position in the market by innovating, while the funding conditions are tight. The IP scenario is characterized by environmental, political and social pressure towards innovation, however, companies do not suffer from limited capacity to access financial and human resources. Prescriptive regulations and standards impact companies involvement in innovation processes under CD development.

Table 2. Analysis of transition pathway scenario opportunities and threats.

\begin{tabular}{lll}
\hline Scenario & Opportunities & Threats \\
\hline Business as & $\bullet$ Optimum control and use of current knowledge and & $\bullet$ Industry stays conservative and passive; \\
usual & • Industry remains fragmented; \\
& $\bullet$ Lack of collaboration between industry and researchers; \\
& $\bullet$ Skilled labor shortages; \\
& $\bullet$ Lack of industry competitiveness; \\
& $\bullet$ Low industry productivity growth.
\end{tabular}




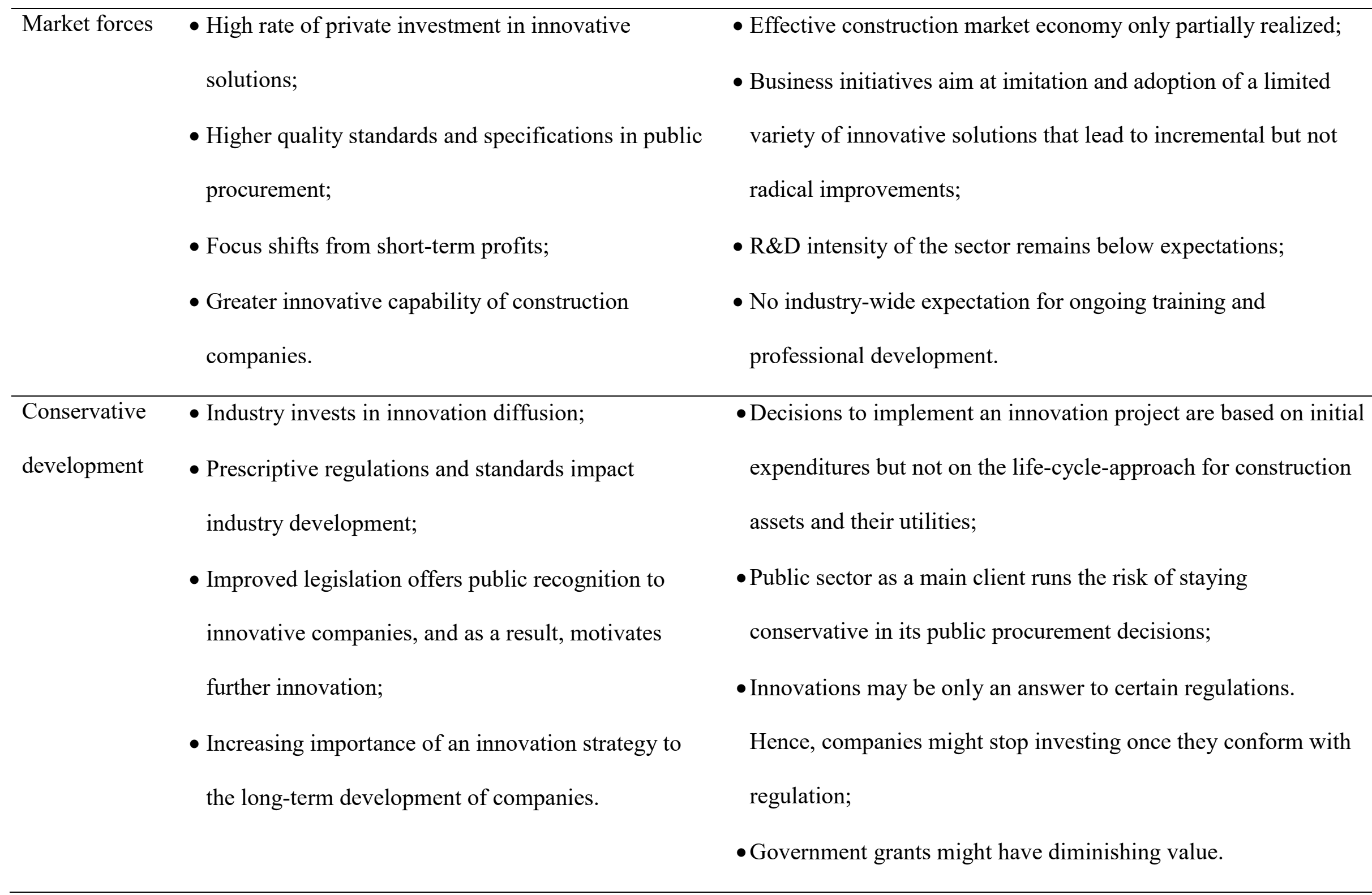


- Reliant on extensive government support over long periods that could be withdrawn.

$\begin{array}{lll}\text { Innovation } & \bullet \text { An improving economy with prospects for } & \bullet \text { Rapid pace of change poses a risk to certain companies not being } \\ \text { power } & \text { significant transformation of the construction } & \text { able to adapt to competitive market conditions quickly enough; } \\ \text { industry; } & \bullet \text { Potential rising costs for land, materials, and labor; } \\ \bullet & \text { Construction firms exploit their full potential for } & \bullet \text { Public financial burden due to the high government expenditure } \\ & \text { innovative solutions and technological changes in a } & \text { on innovation activities; } \\ & \text { strategic manner; } \\ \bullet & \text { Publicly and privately funded R\&D as the financial } \\ & \text { means for R\&D investments are available; } \\ \bullet & \text { Greater number of internationally competitive } \\ & \text { companies exporting construction services. } \\ & \text { Sustained industry investment in R\&D. }\end{array}$




\section{FIGURES}

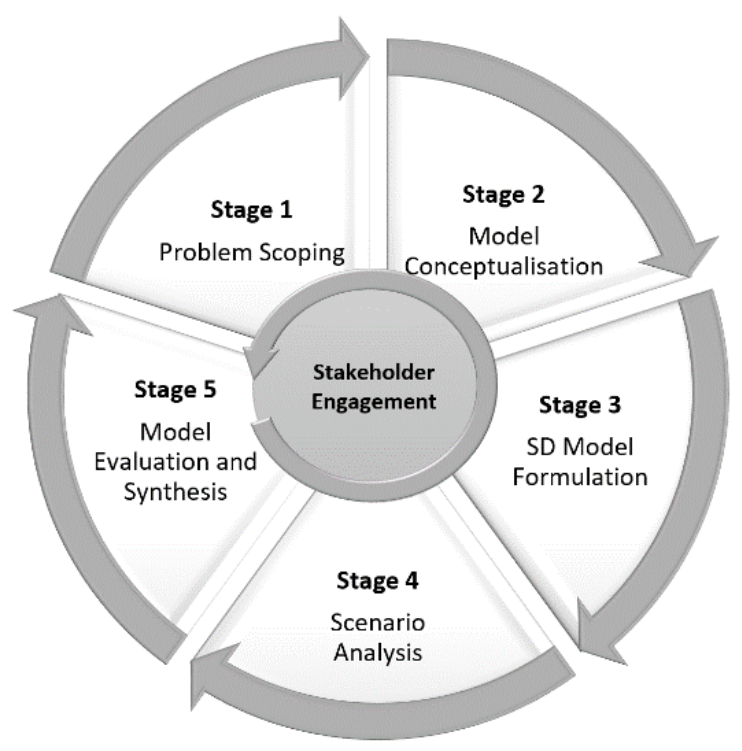

Figure 1. Five-stage IPSM procedure (Adapted from Suprun et al. (2018)).

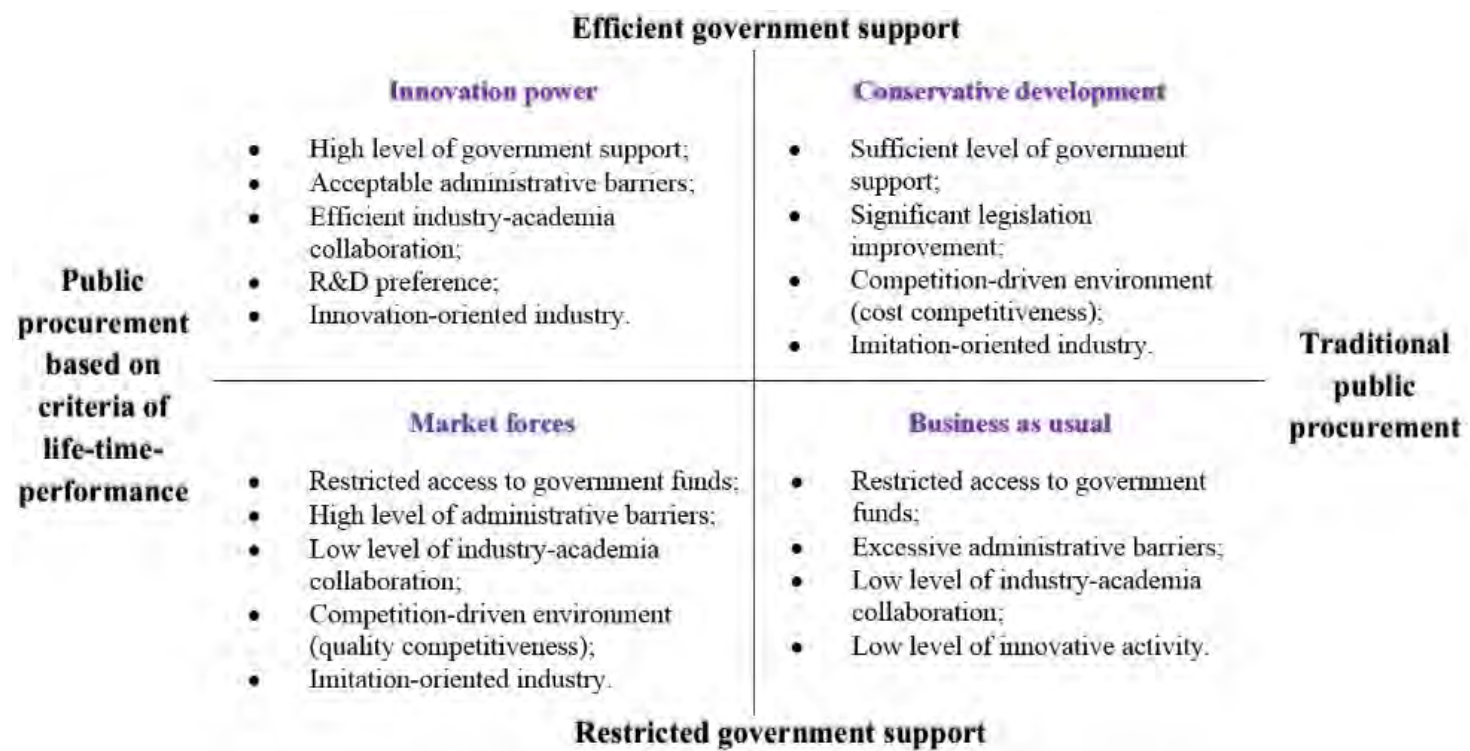

Figure 2. Main characteristics of the transition pathway scenarios. 


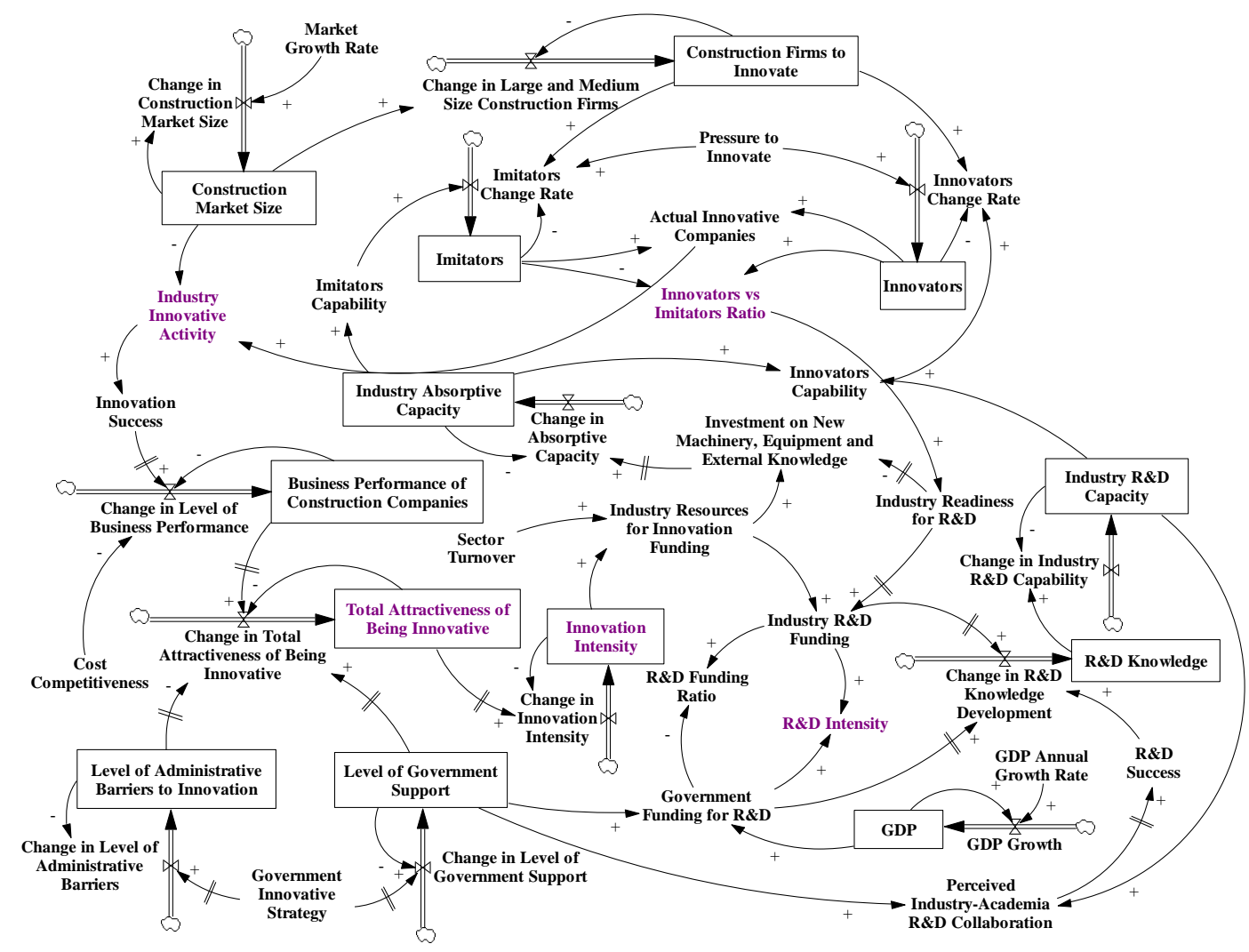

Figure 3. Overview of the SD model.

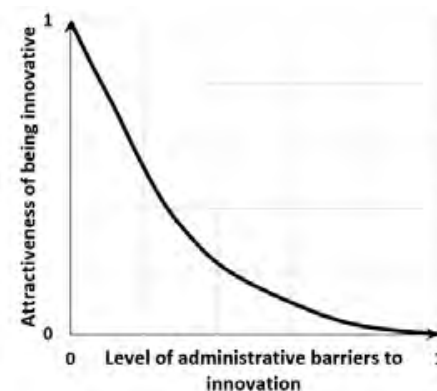

(a)

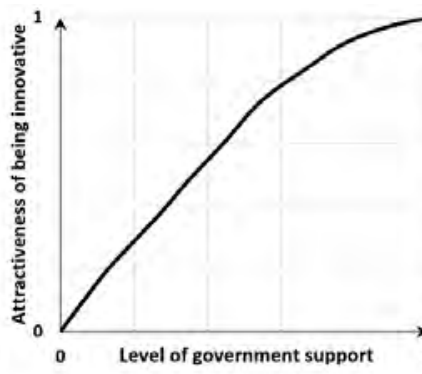

(b)

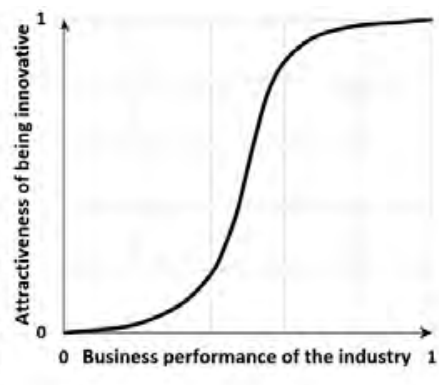

(c)

Figure 4. Graphical representation of a non-linear relationship between the level of attractiveness of innovation and (a) level of administrative barriers, (b) level of government support and (c) business performance of the industry. 


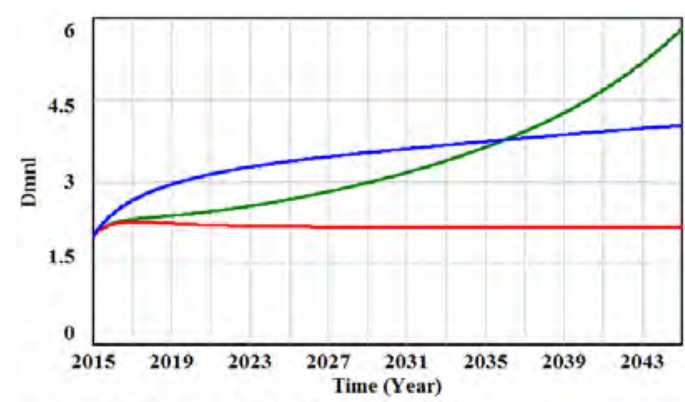

Industry Innovative Activity : Extreme (GDP decrease)

Industry Innovative Activity : Extreme (no support)

Industry Innovative Activity : Base run

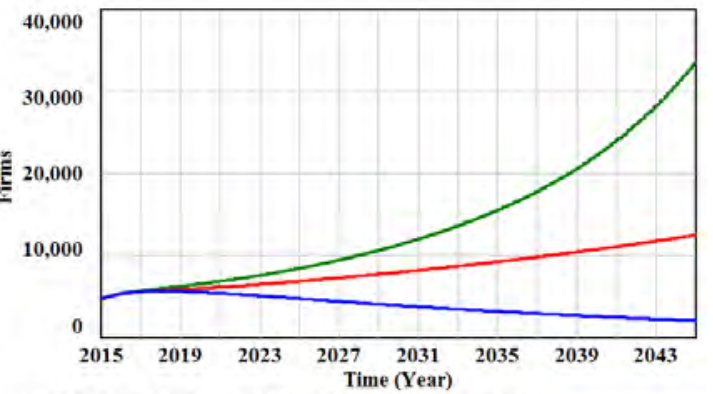

Actual Innovative Companies : Extreme (GDP decrease) Actual Innovative Companies : Extreme (no support) Actual Innovative Companies: Base run

(a)

(b)

Figure 5. Outcomes of extreme condition test. Graph (a) shows the behavior of Industry innovative activity variable under different circumstances. Graph (b) illustrates the behavior of Actual innovative companies under the same circumstances.

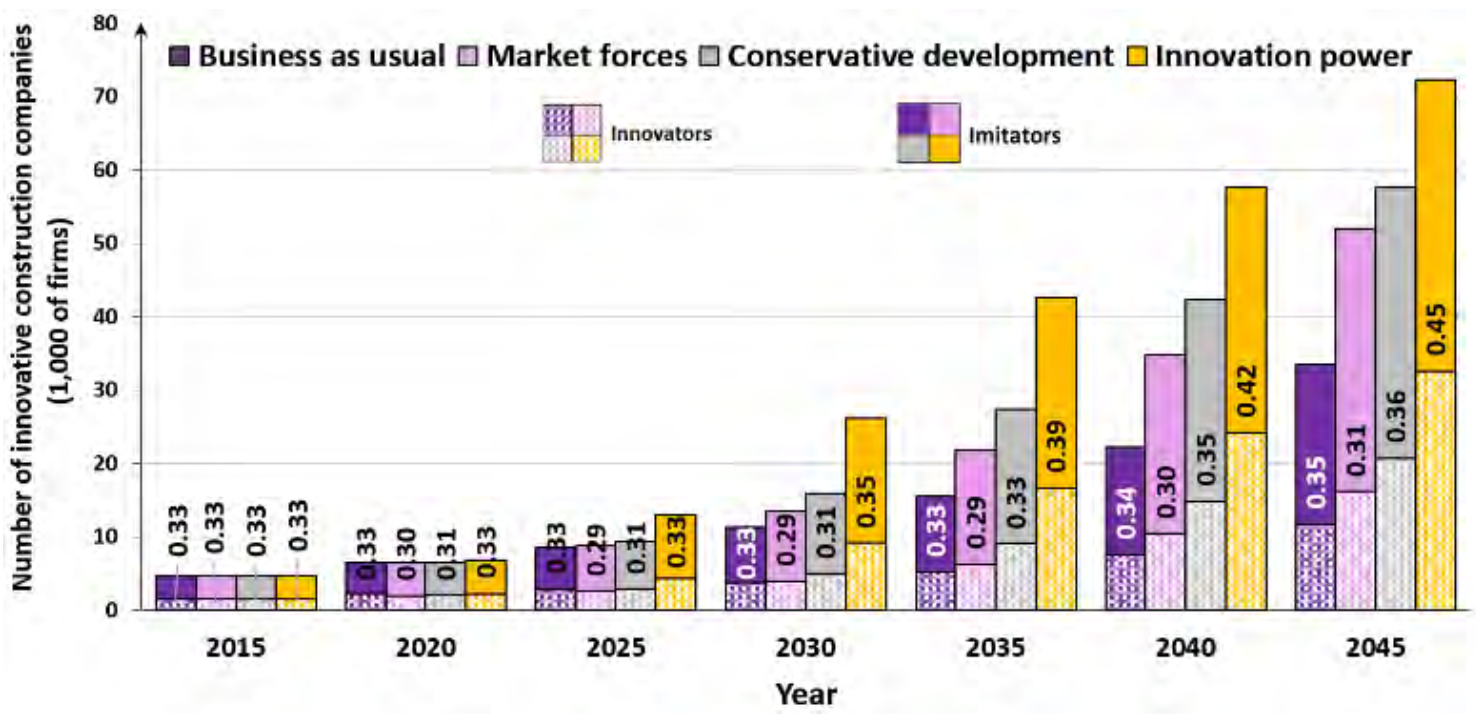

Figure 6. Scenario results for cumulative innovative construction companies. 


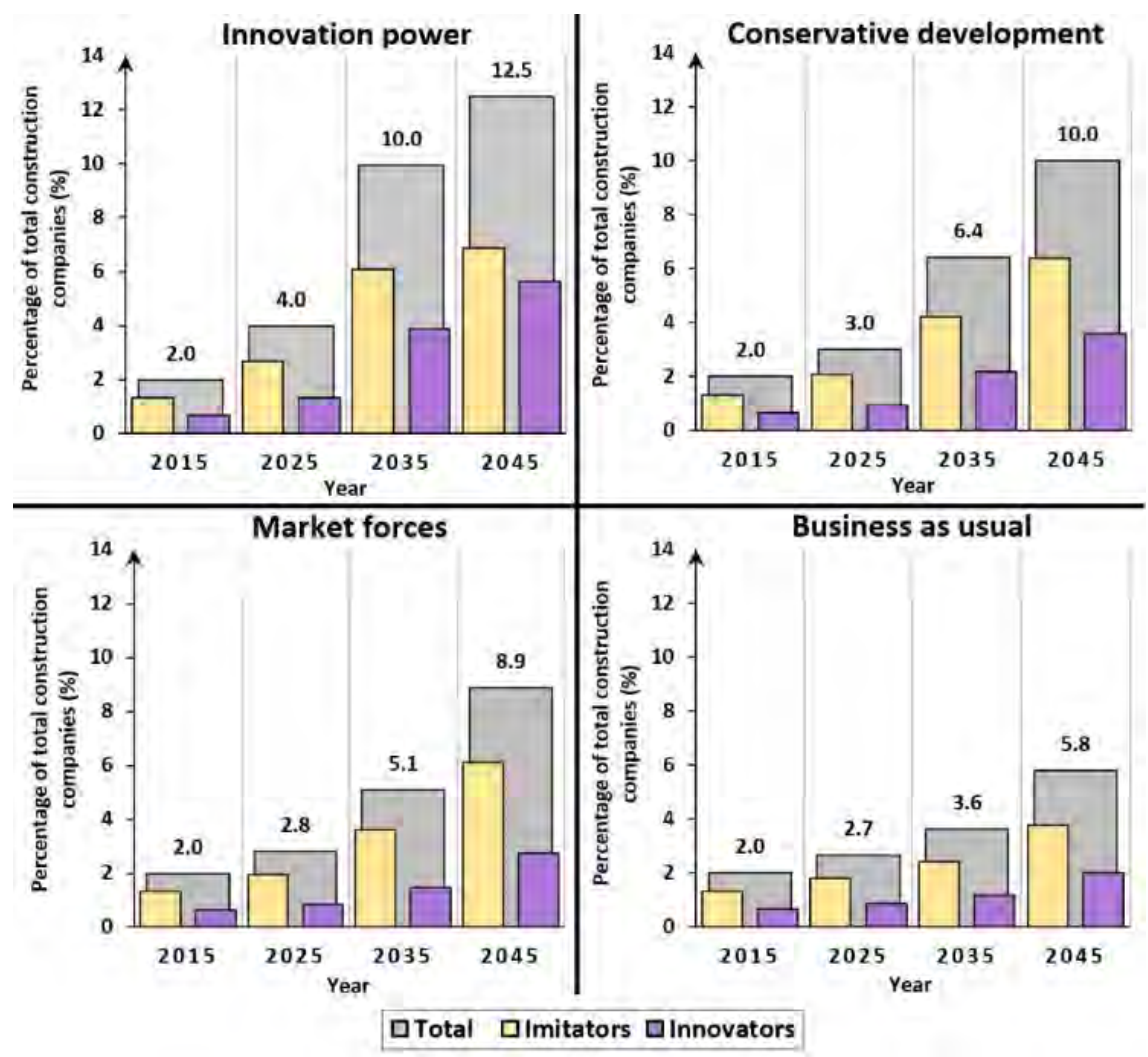

Figure 7. Simulation outcomes under four scenarios: Innovative activity.

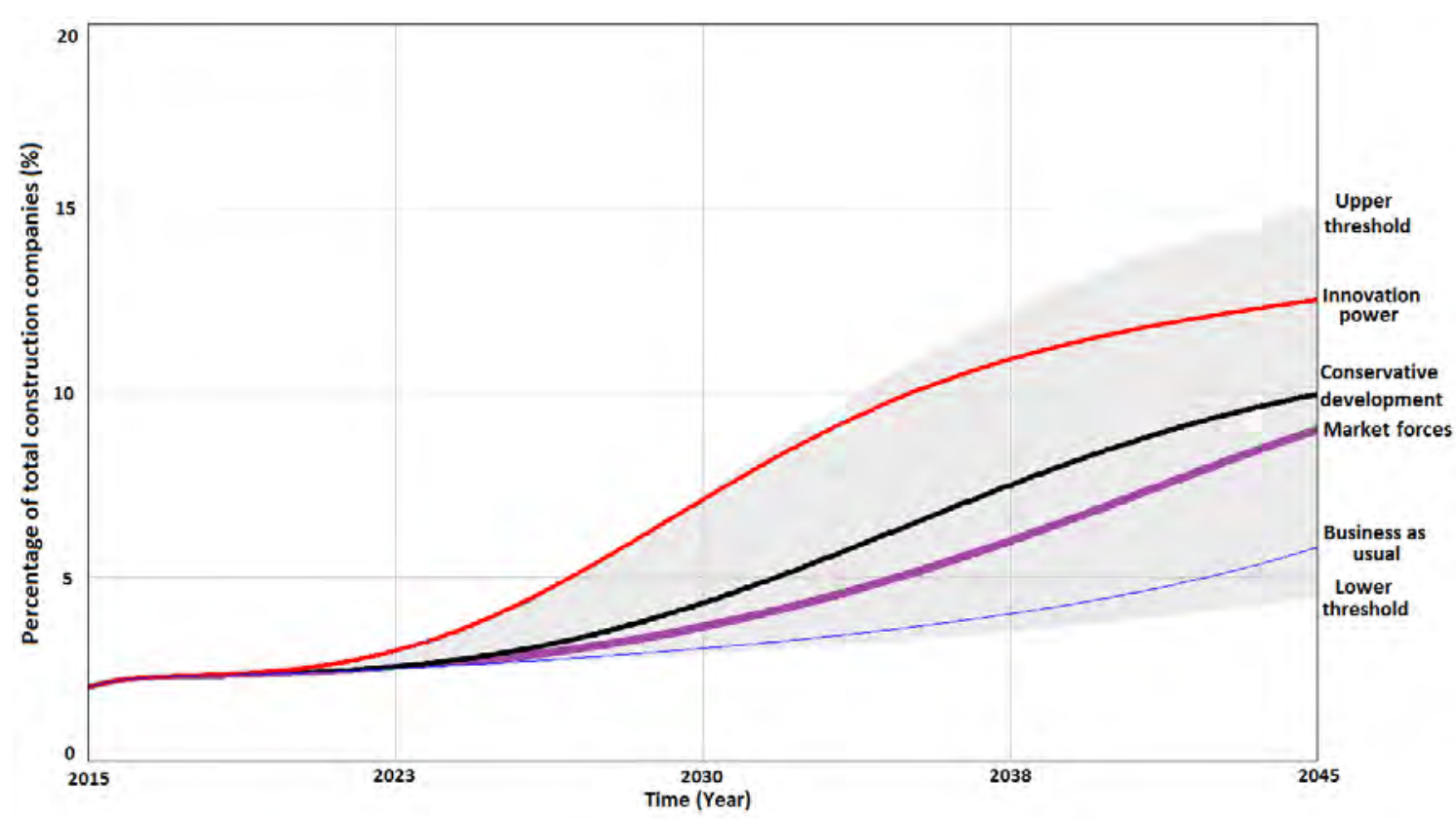

Figure 8. Sensitivity analysis of the model. 


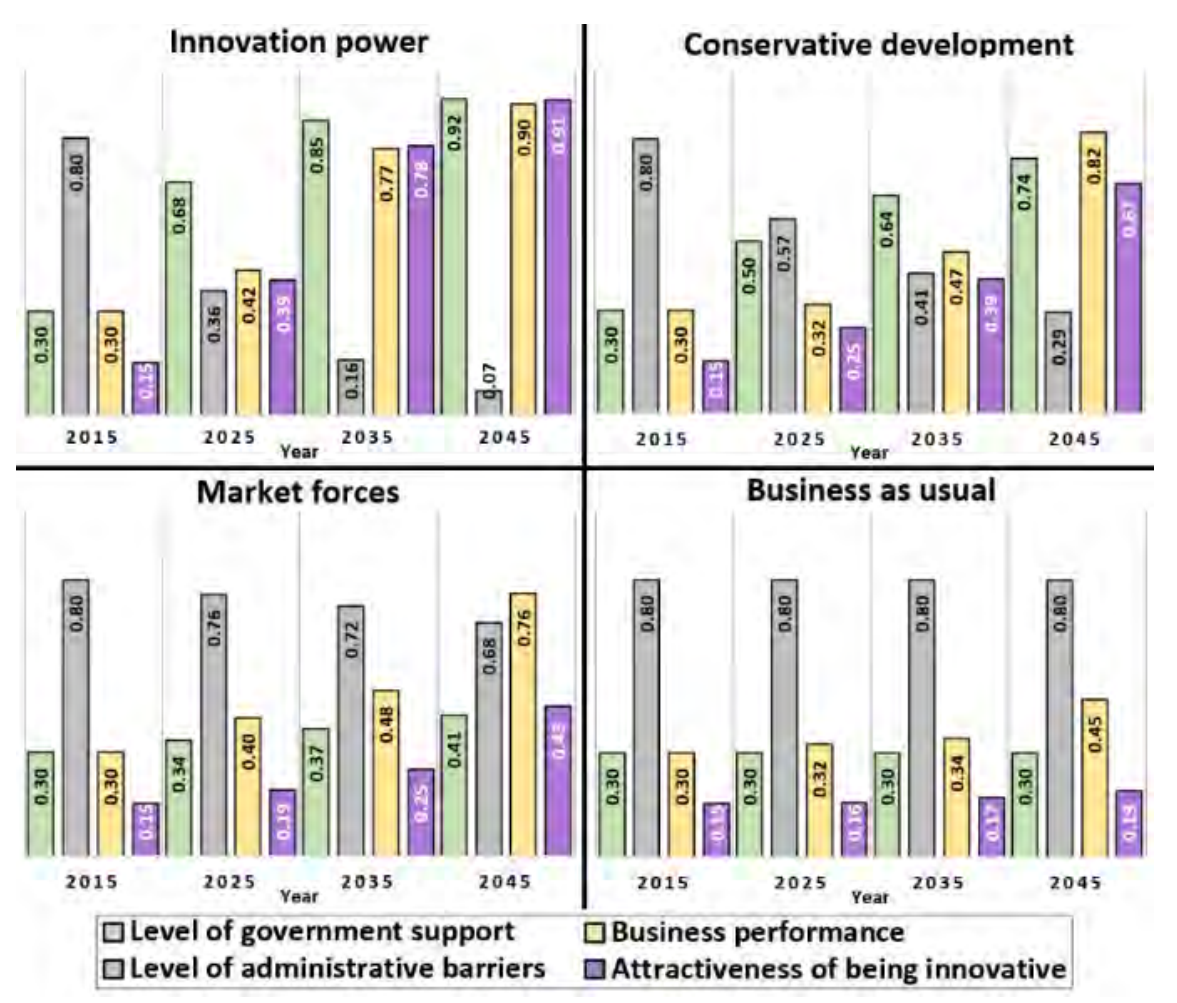

Figure 9. Simulation outcomes under four scenarios: Attractiveness of being innovative index.

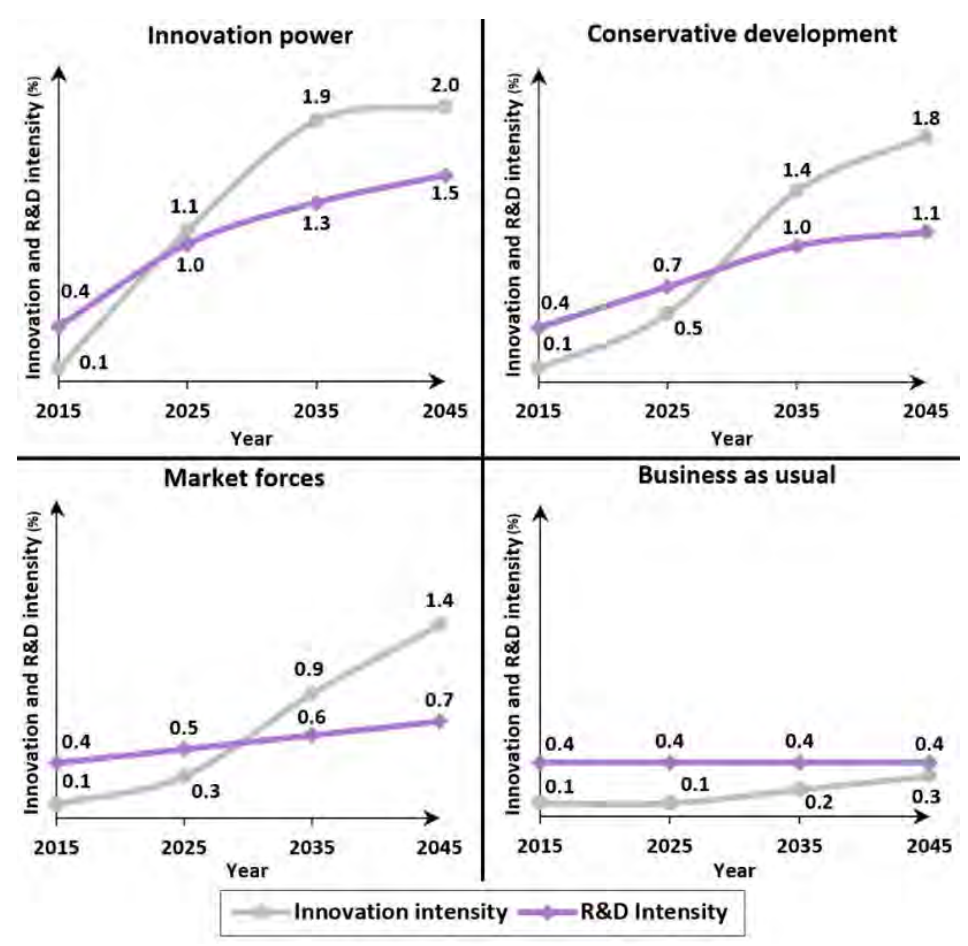

Figure 10. Simulation outcomes under four scenarios: Innovation and R\&D intensity. 


\section{FIGURE CAPTIONS}

Figure 1. Five-stage IPSM procedure (Adapted from Suprun et al. (2018)).

Figure 2. Main characteristics of the transition pathway scenarios.

Figure 3. Overview of the SD model.

Figure 4. Graphical representation of a non-linear relationship between the level of attractiveness of innovation and (a) level of administrative barriers, (b) level of government support and (c) business performance of the industry.

Figure 5. Outcomes of extreme condition test. Graph (a) shows the behavior of Industry innovative activity variable under different circumstances. Graph (b) illustrates the behavior of Actual innovative companies under the same circumstances.

Figure 6. Scenario results for cumulative innovative construction companies.

Figure 7. Simulation outcomes under four scenarios: Innovative activity.

Figure 8. Sensitivity analysis of the model.

Figure 9. Simulation outcomes under four scenarios: Attractiveness of being innovative index.

Figure 10. Simulation outcomes under four scenarios: Innovation and R\&D intensity. 